\title{
Thermodynamic analysis of low GWP alternatives to HFC-245fa in high-temperature heat pumps: HCFO-1224yd(Z), HCFO- $1233 z d(E)$ and HFO-1336mzz(Z)
}

\author{
Carlos Mateu-Royo*, Joaquín Navarro-Esbrí, Adrián Mota-Babiloni, Marta Amat-Albuixech, \\ Francisco Molés \\ ISTENER Research Group, Department of Mechanical Engineering and Construction, \\ Universitat Jaume I, Campus de Riu Sec s/n, E12071 Castellò de la Plana, Spain
}

\begin{abstract}
This paper analyses the feasibility of HCFO-1224yd(Z), HCFO-1233zd(E) and HFO$1336 \mathrm{mzz}(\mathrm{Z})$, three low global warming potential (GWP) refrigerants, as alternatives to HFC$245 \mathrm{fa}$ in high-temperature heat pump (HTHP) systems for low-grade waste heat recovery. HTHPs are a sustainable technology that can help to mitigate the climate change through the thermal valorisation of the industrial low-grade waste heat. Before presenting and analysing the results, mapping of the minimum superheat degree requirement in the operating range, and the influence of the Internal Heat Exchanger (IHX) on each alternative are studied. The simulations were carried out at condensing temperatures from 115 to $145^{\circ} \mathrm{C}$ and evaporating temperatures from 45 to $75^{\circ} \mathrm{C}$, using single-stage cycle with and without IHX. Finally, Total Equivalent Warming Impact (TEWI) evaluation is performed to illustrate the environmental effect of each alternative. Attending to the results, HCFO-1233zd(E) improves the COP about 27\% compared to HFC245fa, whereas HFO-1336mzz(Z) and HCFO-1224yd(Z) show an improvement of approx. 21 and $17 \%$, respectively. Although HCFO-1233zd(E) and HCFO-1224yd(Z) present similar suction volumetric flow rate to $\mathrm{HFC}-245 \mathrm{fa}, \mathrm{HFO}-1336 \mathrm{mzz}(\mathrm{Z})$ shows a relative increment up to $80 \%$, and therefore, higher compressor and installation size are expected for this refrigerant. Finally, the TEWI analysis presents a significant reduction of the equivalent $\mathrm{CO}_{2}$ emissions for each low GWP alternative, between 59 and $61 \%$. HCFO-1233zd(E) shows the highest reduction in all the simulation cases, followed by HCFO-1224yd(Z) and HFO-1336mzz(Z).
\end{abstract}

Keywords: low-grade waste heat recovery; HTHP; liquid-to-suction heat exchanger; energy efficiency; vapour compression system; climate change mitigation

\section{Nomenclature}

\begin{tabular}{|ll|}
\hline$a, b, k_{e}, k_{s}, k_{1}, k_{2}$ & Pierre's correlations constants \\
$\mathrm{COP}$ & coefficient of performance $(-)$ \\
$\mathrm{E}_{\mathrm{a}}$ & annual energy consumption $(\mathrm{kWh})$ \\
$h$ & enthalpy $\left(\mathrm{kJ} \mathrm{kg}^{-1}\right)$ \\
$\mathrm{L}$ & annual refrigerant leakage rate $\left(\mathrm{kg} \mathrm{year}^{-1}\right)$ \\
$m$ & total refrigerant charge of the system $(\mathrm{kg})$ \\
$\dot{m}$ & refrigerant mass flow rate $\left(\mathrm{kg} \mathrm{s}^{-1}\right)$ \\
$M$ & molecular weight $\left(\mathrm{g} \mathrm{mol}^{-1}\right)$ \\
$\mathrm{n}$ & lifespan of the vapour compression system (years) \\
$P$ & pressure $(\mathrm{MPa})$ \\
$P r$ & Prandtl number $(-)$ \\
$T$ & temperature $\left({ }^{\circ} \mathrm{C}\right)$ \\
$\mathrm{VHC}$ & volumetric heating capacity $\left(\mathrm{kJ} \mathrm{m}{ }^{-3}\right)$ \\
$\dot{Q}$ & heat transfer $(\mathrm{kW})$ \\
$\dot{V}$ & volumetric flow rate $\left(\mathrm{m}^{3} \mathrm{~s}^{-1}\right)$ \\
$\dot{W}$ & electric power consumption $(\mathrm{kW})$ \\
\hline
\end{tabular}

\footnotetext{
* Corresponding author: Carlos Mateu-Royo

Email: mateuc@uji.es
} 


\begin{tabular}{|ll|}
\hline Greek symbols & \\
$\varepsilon$ & effectiveness $(-)$ \\
$\eta$ & efficiency $(-)$ \\
$\rho$ & density $\left(\mathrm{kg} \mathrm{m}^{-3}\right)$ \\
$\alpha$ & recycling factor of the refrigerant $(\%)$ \\
$\beta$ & indirect emission factor $\left(\mathrm{kgCO}_{2} \mathrm{kWh}^{-1}\right)$ \\
& \\
Subscripts & \\
c & compressor \\
cond & condensation \\
crit & critical \\
em & electromechanical \\
evap & evaporation \\
in & inlet \\
is & isentropic \\
$\mathrm{k}$ & condenser \\
o & evaporator \\
out & outlet \\
pb & pool boiling \\
r & reduced \\
suc & suction \\
vol & volumetric \\
& \\
Abbreviations & \\
AEL & atmospheric exposure level \\
CFC & chlorofluorcarbon \\
FOM & figure of merit \\
GWP & global warming potential \\
HCFO & hydrochlorofluoro-olefin \\
HFC & hydrofluorocarbon \\
HTHP & high-temperature heat pump \\
IHX & internal heat exchanger \\
TEWI & total equivalent warming impact \\
ODP & ozone depletion potential \\
SPHT & single-phase heat transfer \\
\hline & \\
\hline
\end{tabular}

\section{Introduction}

The concern for global warming has raised awareness about the importance of climate change mitigation during the last decades. This was evidenced in the Paris Agreement through which around 200 nations established the long-term objective of maintaining the increase in global average temperature below $2{ }^{\circ} \mathrm{C}$ above pre-industrial levels by 2100 . Moreover, the Parties noted the relevance of promoting the mitigation of greenhouse gas (GHG) emissions while fostering sustainable development [1]. According to the Fifth Assessment Report (AR5) of the Intergovernmental Panel on Climate Change (IPCC), the industry is a critical factor for climate change control since their GHG emissions have been doubled between 1970 and 2010 [2].

Therefore, from the analysis of the industrial energy demand, it can be observed that most of the consumption comes from thermal processes at temperatures above $100{ }^{\circ} \mathrm{C}$. It is mostly provided through fossil fuels combustion with uncertain acquisition prices and severe environmental impacts such as climate change. Moreover, a significant fraction (around 2.8\%) of the industrial energy consumption is wasted as low-grade heat below $100{ }^{\circ} \mathrm{C}$, Fig. 1 [3]. Recovering the lowgrade waste heat (below $100^{\circ} \mathrm{C}$ ) and transforming it into useful heat at the required temperature (above $100^{\circ} \mathrm{C}$ ) by means of energy efficient technologies would increase the energy efficiency 
and decarbonise the industrial sector. An option to use a vapour compression high-temperature heat pump (HTHP), which can be integrated into different industrial and district heating processes due to the flexibility that offers in possible operating temperatures and heat capacities.

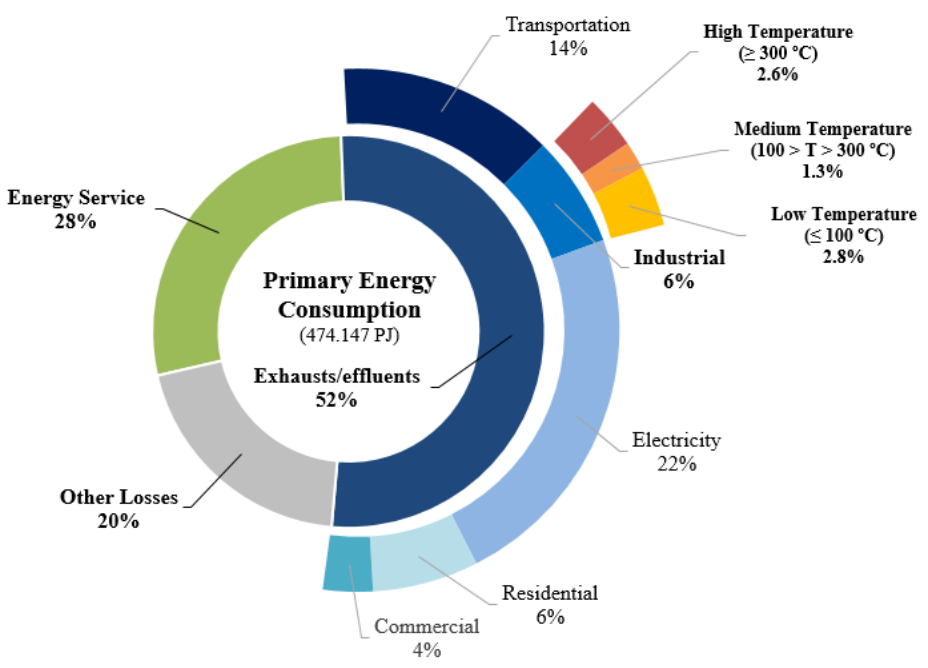

Fig. 1. Energy consumption breakdown and potential industrial low-grade waste heat [3].

The firstly developed HTHPs used CFC-114 [4] (chlorofluorocarbon), CFC-113 [5], and HCFC123 [6] as refrigerants (working fluids). Nevertheless, according to the Montreal Protocol, the substances that deplete the ozone layer must be phased out [7], and other chlorine-free refrigerants appeared to be used in these applications. Therefore, Brown [8] evaluated 56 potential CFC-114 replacement refrigerants for HTHP applications and identified HFC-245fa for high-pressure operation. HFC-245fa has a relatively high critical temperature $\left(154{ }^{\circ} \mathrm{C}\right)$, zero ozone depletion potential (ODP), and is the most commonly used third generation working fluid for HTHPs today [9].

However, in 2014, EU Regulation No. 517/2014 [10] gradually limited the hydrofluorocarbons (HFCs) allowed in most of the vapour compression systems and established market quotas to their consumption. Hence, low global warming potential (GWP) alternatives (named as fourth generation refrigerants by Calm [11]) are necessary to replace HFC-245fa, which has a GWP value of 858. Natural refrigerants [12], hydrofluoroolefin (HFO) and hydrochlorofluorocarbon (HCFO) are becoming relevant for the today HTHPs. Due to the thermodynamic similarity with HFC-245fa, low GWP organic refrigerants (HFOs and HCFOs) receive more attention for hightemperature applications.

Tetrafluoropropene and its isomers were the first low GWP alternatives considered for HTHPs. Brown et al. [13] studied HFO-1234ze(Z) as a potential alternative for CFC-114 because of its similar thermodynamic and transport properties. Fukuda et al. [14] and Kondou et al. [15] performed a theoretical thermodynamic comparison using HFO-1234ze(E) and HFO-1234ze(Z). The results highlight HFO-1234ze(Z) as the most suitable low GWP refrigerant for HTHPs. Despite the satisfactory thermodynamic properties of HFO-1234ze(Z), it is still not commercially available. In addition, the isomer HFO-1234ze(E), which is commercially available [16], presents a critical temperature of $109.4{ }^{\circ} \mathrm{C}$ and it is more suitable for condensation temperatures up to 100 ${ }^{\circ} \mathrm{C}$. Hence, both fluids are not considered as possible alternatives and other refrigerant candidates are receiving special attention in the last years. 
HFO-1336mzz(Z) and HCFO-1233zd(E) are the most studied refrigerants today, whereas the recently developed HCFO-1224yd(Z) is becoming a potential alternative, but none studies have been found for this refrigerant. Table 1 shows the evolution of the characteristics for the main refrigerants used in HTHPs as well as the potential candidates for replacing HFC-245fa.

Table 1. Evolution of the main refrigerants used in high-temperature heat pumps.

\begin{tabular}{|c|c|c|c|}
\hline Refrigerant no & ODP & GWP & $\begin{array}{c}\text { ASHRAE } \\
\text { Std. 34 safety } \\
\text { class [29] }\end{array}$ \\
\hline CFC-114 & 0.5 & 8590 & A1 \\
\hline CFC-113 & 0.81 & 5820 & A1 \\
\hline HCFC-123 & 0.01 & 79 & B1 \\
\hline HFC-245fa & 0 & 858 & B1 \\
\hline HFO-1336mzz(Z) & 0 & 2 & A1 \\
\hline HCFO-1233zd(E) & 0.00034 & 1 & A1 \\
\hline HCFO-1224yd(Z) & 0.00012 & $<1$ & A1 \\
\hline
\end{tabular}

Kontomaris proposed $\mathrm{HFO}-1336 \mathrm{mzz}(\mathrm{Z})$ as a refrigerant candidate for high-temperature applications with condensing temperatures above $100{ }^{\circ} \mathrm{C}$. It shows $2.3 \%$ theoretical higher coefficient of performance (COP) than HFC-245fa [17] and presents high chemical stability, very low GWP, no-ODP, no flammability and compatibility with many plastics and elastomers [18] and with commercially available polyolester (POE) lubricants [19].

On the other hand, Gorgy [20] proved that HCFO-1233zd(E) shows 19\% higher heat transfer performance than HCFC-123 and Byun et al. [21] performed a similar study about the HCFO$1233 \mathrm{zd}(\mathrm{E})$ heat transfer performance. Although it has not been yet tested in HTHPs, it shows excellent performance and heat transfer results in other high-temperature applications [22]. Nevertheless, Lee et al. [23] performed an experimental study of the pressure drop and heat transfer of HCFO-1223zd(E) compared with HFC-245fa. This study shows that similar pressure drops and a reduction of $9 \%$ of the heat transfer are expected. When compared with HFC-245fa in different HTHP configurations, HCFO-1233zd(E) highlighted in volumetric heating capacity (VHC) whereas HFO-1336mzz(Z) provides intermediate values in VHC and COP [24]. Thus, both become potential substitutes of HFC-245fa.

HCFO-1224yd(Z) ((Z)-1-chloro-2,3,3,3-tetrafluoropropene, $\mathrm{CF} 3 \mathrm{CF}=\mathrm{CHCl})$ is an unsaturated organic compound approved in 2017 by the American Society of Heating, Refrigerating, and Air Conditioning Engineers (ASHRAE) [25] and proposed for HFC-245fa replacement in applications like centrifugal chillers, binary cycle generators and HTHPs. The main reasons for this statement are that its GWP value is below the unity [26] and it is considered a low-pressure refrigerant, as HFC-245fa. HCFO-1224yd(Z) is the last pure fluid HTHP candidate approved by the ASHRAE, and due to the recent certification of this refrigerant, there are not available results about the HTHP performance using it. For the moment, only Masato et al. [27] published the experimental thermodynamic properties (vapour pressure and the PVT properties, vapour-liquid and coexistence curve saturated liquid densities, and critical temperature, density and pressure) of HCFO-1224yd(Z). From that information, this refrigerant shows closer thermodynamic properties to HFC-245fa, and therefore can be an excellent candidate to replace it in existing, redesigned or even new HTHP systems. Before to the experimentation with the refrigerant, the more appropriate operating temperature range and configuration need to be theoretically verified.

Given the number of environmentally friendly alternatives to HFC-245fa in HTHP systems developed in the last years and the lack of information, this paper analyses and compares the operating and energetic performance of HFO-1336mzz(Z), HCFO-1233zd(E) and HCFO$1224 \mathrm{yd}(\mathrm{Z})$ as a potential low GWP alternatives to replace the commonly used HFC-245fa refrigerant in high-temperature heat pumps (HTHPs). In addition, this paper provides a complete 
overview of the consequences of the HFC-245fa replacement, comparing the main thermodynamic and transport properties of the alternatives proposed and the influence the internal heat exchanger (IHX). This paper aims to provide comparative information of these recently developed working fluids and can be used as a guide to decide the refrigerant to use in any specific HTHP application, depending on the safety requirements, operating range of temperatures and pressures, and energy performance priorities.

\section{Properties Evaluation of the Proposed low GWP Refrigerants}

The low GWP refrigerants evaluated in this paper to replace HFC-245fa are HFO-1336mzz(Z), HCFO-1233zd(E) and HCFO-1224yd(Z). Table 2 shows the main properties of these fluids from REFPROP Version 10 [28]. This information is then used to compare some of their characteristics and predict the possible behaviour in the cycle analysis.

Table 2. Properties of low GWP refrigerants and HFC-245fa.

\begin{tabular}{|c|c|c|c|c|}
\hline Parameters & $\begin{array}{l}\text { HFC- } \\
245 f a\end{array}$ & $\begin{array}{c}\text { HFO- } \\
1336 \mathrm{mzz}(\mathrm{Z})\end{array}$ & $\begin{array}{c}\text { HCFO- } \\
\text { 1233zd(E) }\end{array}$ & HCFO-1224yd(Z) \\
\hline $\begin{array}{l}\text { Molecular weight } \\
\left(\mathrm{g} \cdot \mathrm{mol}^{-1}\right)\end{array}$ & 134.05 & 164.06 & 130.50 & 148.49 \\
\hline $\begin{array}{c}\text { Critical } \\
\text { temperature }\left({ }^{\circ} \mathrm{C}\right)\end{array}$ & 153.86 & 171.35 & 166.45 & 155.54 \\
\hline $\begin{array}{c}\text { Critical pressure } \\
(\mathrm{MPa})\end{array}$ & 3.65 & 2.90 & 3.62 & 3.34 \\
\hline $\begin{array}{l}\text { Normal boiling } \\
\text { point }(\mathrm{NBP})\left({ }^{\circ} \mathrm{C}\right)\end{array}$ & 15.05 & 33.45 & 18.26 & 14.62 \\
\hline $\begin{array}{l}\text { Tested thermal } \\
\text { stability }\left({ }^{\circ} \mathrm{C}\right)\end{array}$ & 250 & 250 & 175 & 175 \\
\hline $\begin{array}{c}\text { Condensing } \\
\text { pressure }^{\mathrm{a}}(\mathrm{MPa})\end{array}$ & 2.35 & 1.35 & 1.91 & 2.11 \\
\hline Pressure Ratio ${ }^{\mathrm{a}, \mathrm{b}}$ & 5.08 & 5.52 & 4.88 & 4.80 \\
\hline $\begin{array}{c}\text { Vapour pressure } \\
(\mathrm{MPa})\end{array}$ & 0.15 & 0.07 & 0.13 & 0.15 \\
\hline $\begin{array}{l}\text { Latent heat of } \\
\text { vaporization } \\
\left(\mathrm{kJ} \cdot \mathrm{kg}^{-1}\right)\end{array}$ & 169.12 & 151.33 & 171.24 & 145.21 \\
\hline $\begin{array}{l}\text { Latent heat of } \\
\text { condensation } \\
\left(\mathrm{kJ} \cdot \mathrm{kg}^{-1}\right)\end{array}$ & 97.25 & 102.34 & 111.53 & 86.10 \\
\hline $\begin{array}{l}\text { Suction density } \\
\left(\mathrm{kg} \cdot \mathrm{m}^{-3}\right)\end{array}$ & 25.45 & 16.02 & 20.73 & 27.11 \\
\hline $\begin{array}{c}\text { Liquid/Vapour } \\
\text { density }^{\mathrm{a}}\left(\mathrm{kg} \cdot \mathrm{m}^{-3}\right)\end{array}$ & $\begin{array}{c}938.36 / \\
156.10 \\
\end{array}$ & $1014.10 / 96.36$ & $\begin{array}{c}926.88 / \\
113.52 \\
\end{array}$ & 958.53 / 154.63 \\
\hline $\begin{array}{c}\text { Liquid/Vapour } \\
\text { specific heat } \\
\left(\mathrm{kJ} \cdot \mathrm{kg}^{-1} \cdot \mathrm{K}^{-1}\right)\end{array}$ & $\begin{array}{l}1.98 / \\
1.87\end{array}$ & $1.57 / 1.37$ & $1.64 / 1.42$ & $1.64 / 1.56$ \\
\hline $\begin{array}{l}\text { Specific heat } \\
\text { ratio }^{\mathrm{b}}\end{array}$ & 1.44 & 1.10 & 1.45 & 1.14 \\
\hline $\begin{array}{c}\text { ODP }(\mathrm{CFC}-11=1) \\
{[29]}\end{array}$ & 0 & 0 & 0.00034 & 0.00012 \\
\hline $\mathrm{GWP}_{100 \text {-years }}[29]$ & 858 & 2 & 1 & $<1$ \\
\hline $\begin{array}{l}\text { Atmospheric } \\
\text { lifetime [29] }\end{array}$ & 7.7 years & 26 days & 26 days & 21 days \\
\hline
\end{tabular}




\begin{tabular}{|c|c|c|c|c|}
\hline $\begin{array}{c}\text { ASHRAE Std. 34 } \\
\text { safety class [29] }\end{array}$ & B1 & A1 & A1 & A1 \\
\hline $\begin{array}{c}\text { AEL (ppm) } \\
{[17,26]}\end{array}$ & 300 & 500 & 800 & 1000 \\
\hline
\end{tabular}

${ }^{\text {a }}$ At condensing temperature of $130^{\circ} \mathrm{C}$

${ }^{\mathrm{b}}$ At evaporation temperature of $60^{\circ} \mathrm{C}$

${ }^{c}$ At ambient temperature of $25^{\circ} \mathrm{C}$

All the fluids analysed in the study are dry fluids (dT/ds $>0)$, presenting a positive slope of the saturation curves in the T-s diagram, Fig. 2a. Due to this fact, a particular superheating control should be required to ensure the dry compression at high-temperature lifts in order to prevent the presence of liquid drops and possible damage to the compressor [30]. HCFO-1224yd(Z) and HCFO-1233zd(E) have similar T-s saturation curve slopes to HFC-245fa and, being low the dT/ds value, a minimum superheating degree is required for dry compression. In contrast, HFO$1336 \mathrm{mzz}(\mathrm{Z})$ needs a higher superheating degree to ensure a dry compression, requiring a modified vapour compression cycle [30]. For instance, this modification can be performed merely by adding an IHX, which can simultaneously increase the superheat of the suction vapour and the sub-cooling of the liquid refrigerant before the expansion valve [31]. This is the reason why an IHX analysis has been included in this paper, having a more complete and realistic analysis of the potential low GWP alternatives to HFC-245fa.

The operating pressure of all the potential alternatives is below the HFC-245fa, as shown in Fig. $2 \mathrm{~b}$. Therefore, the same security components and adjustments of HFC-245fa can be used with these alternative working fluids and lower refrigerant losses can be expected in case of leakage.

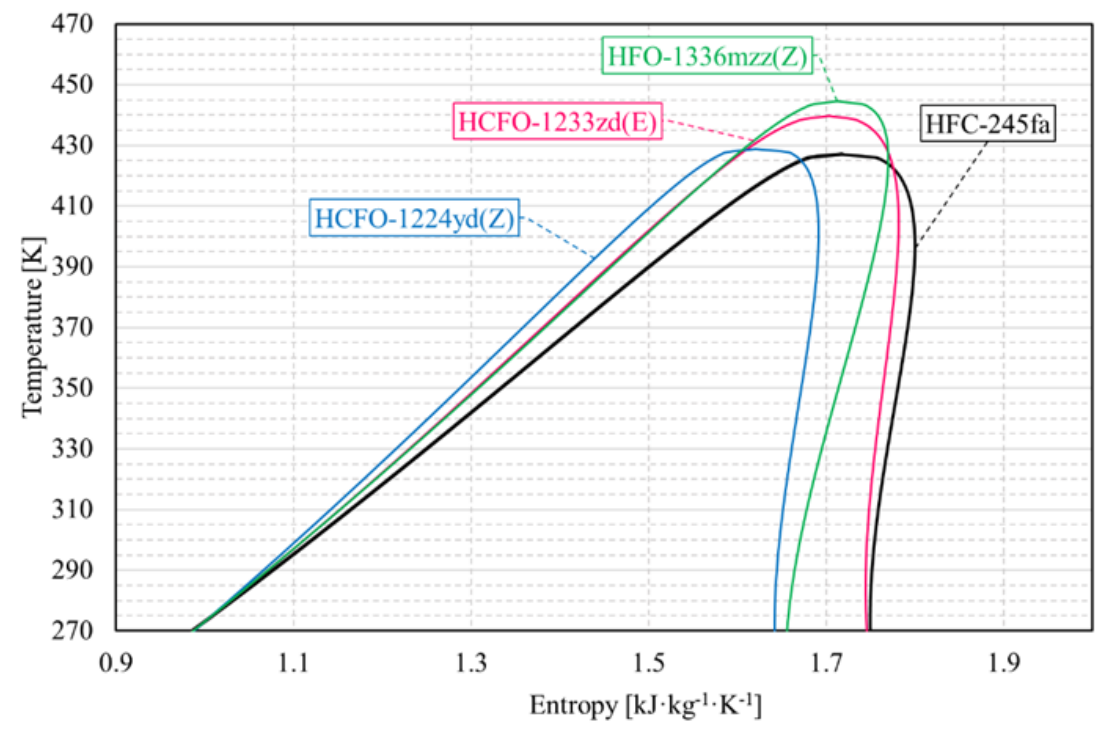

(a) 


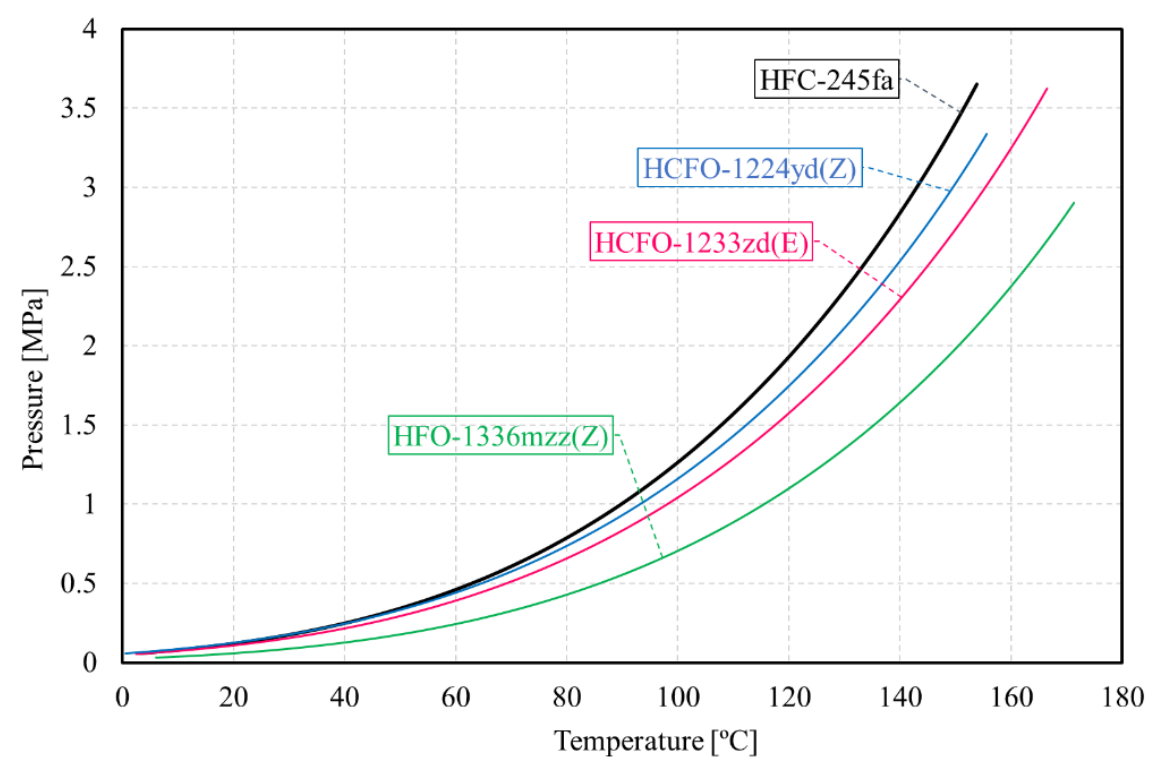

(b)

Fig. 2. a) T-s curves of the potential working fluids alternatives to HFC-245fa and b) Saturated vapour pressure over the operating range temperatures.

All the proposed alternatives have a higher critical temperature than HFC-245fa. Whereas HCFO$1224 \mathrm{yd}(\mathrm{Z})$ has a slight increment of $1.7^{\circ} \mathrm{C}$ compared to the reference fluid, HCFO-1233zd(E) and HFO-1336mzz(Z) show an increase of 12.6 and $17.5^{\circ} \mathrm{C}$, respectively. Therefore, all the alternatives proposed could achieve higher heating production temperatures in future developments, expanding the present operating map of the HTHPs.

Another important aspect is the normal boiling point (NBP) in order to avoid air infiltrations during system operation and downtime [32]. While the vapour NBP of HCFO-1233zd(E) and HCFO-1224yd(Z) are near that of HFC-245fa and below $25^{\circ} \mathrm{C}$, HFO-1336mzz(Z) has a higher $\operatorname{NBP}\left(33.45^{\circ} \mathrm{C}\right)$ with the consequent risk of air infiltrations.

HFO-1336mzz(Z) decreases the liquid density around $8 \%$, reducing the required refrigerant charge compared to HFC-245fa. In contrast, the other refrigerants result in a minor difference of this parameter, and therefore, the amount of refrigerant charge is going to be similar to HFC$245 \mathrm{fa}$. The highest difference is observed in the vapour density, which can affect the resulting refrigerant mass flow rate using the same compressor. In case of the same compressor swept volume, HFO-1336mzz(Z) and HCFO-1233zd(E) are going to decrease the mass flow rate compared to HFC-245fa due to the $38 \%$ and $27 \%$ (respectively) reduction in vapour density. HCFO-1224yd(Z) shows a slight increase of the vapour density.

All the alternatives are non-flammable and low-toxic, obtaining an A1 classification. Although HFO-1336mzz(Z) has zero ODP, HCFO-1233zd(E) and HCFO-1224yd(Z) contain chlorine molecule in their composition, showing an ODP of 0.00034 and 0.00012 , respectively. Nevertheless, the effect of the leakage of these refrigerants on the atmospheric ozone atmosphere is unlikely can be considered negligible [32].

Additionally, the very low GWP values of the alternative refrigerants can substantially reduce the direct contribution to the greenhouse effect in the case of accidental leakage. Considering only the GWP value, the environmental benefit could be clear. However, the greenhouse gas liberation of fossil fuels burning for electricity generation must be accounted to calculate the total contribution to the greenhouse effect [33]. Therefore, the energy performance of HTHP systems using these new refrigerants must be studied in deep. 
Finally, an essential parameter for these new refrigerants is the thermal stability and compatibility with the installation materials and the lubricants. Laboratory tests have shown that HFO$1336 \mathrm{mzz}(\mathrm{Z})$ has a similar material and lubricant compatibility relative to copper and steel to that presented by HFC-245fa, which is widely used in high-temperature applications. Moreover, the thermal stability of $\mathrm{HFO}-1336 \mathrm{mzz}(\mathrm{Z})$ has been successfully tested up to $250^{\circ} \mathrm{C}$ [30]. Although HCFO-1233zd(E) and HCFO-1224yd(Z) present good compatibility with most commonly used metals, plastics, elastomers and POEs lubricant, the copper and steel thermal studies showed turbidity and discolouration after 7 days at $250^{\circ} \mathrm{C}$. Nevertheless, these refrigerants prove thermal stability until $175^{\circ} \mathrm{C}[26,34]$.

\section{System description and modelling}

The single-stage cycle is the system architecture selected in this paper (Fig. 3a) because for its simplicity and robustness, it can be used as a baseline for future installation design and experimental tests. Then, a heat exchanger can be added to the single-stage cycle configuration between the suction and the liquid line (Fig. 3b) to enhance the energy performance of the system. It is known as internal heat exchanger (IHX) and at the same time heats the suction vapour (superheat) and reduces the liquid temperature before the expansion valve (sub-cooling). In contrast to refrigeration systems [34], IHX for HTHPs becomes more interesting for increasing the discharge temperature and the superheat degree than the sub-cooling degree. Higher discharge temperature increases the thermal level of heat production and expands the operating map of the HTHP (always considering the temperature restriction of the components).
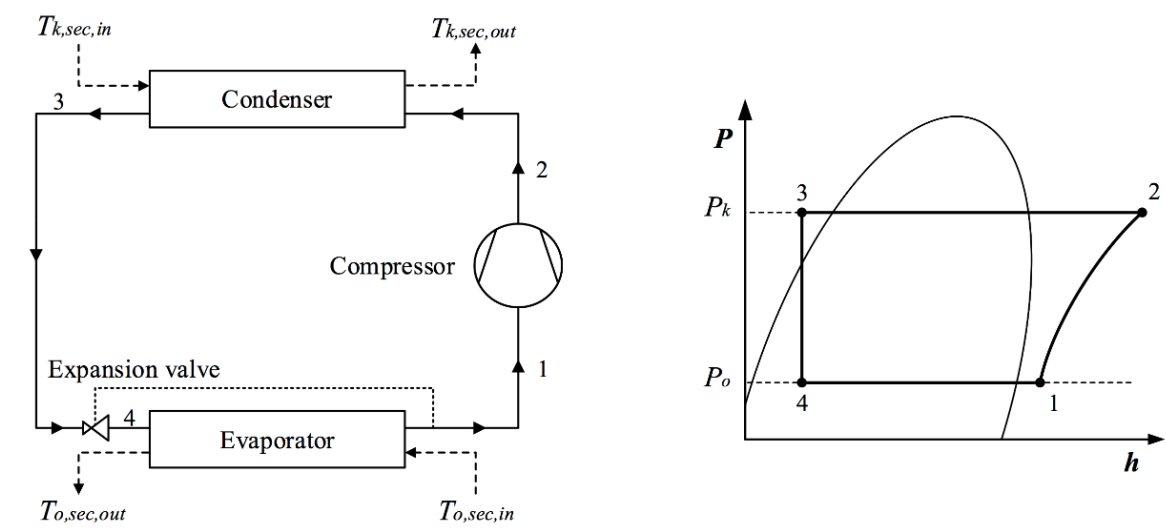

(a)
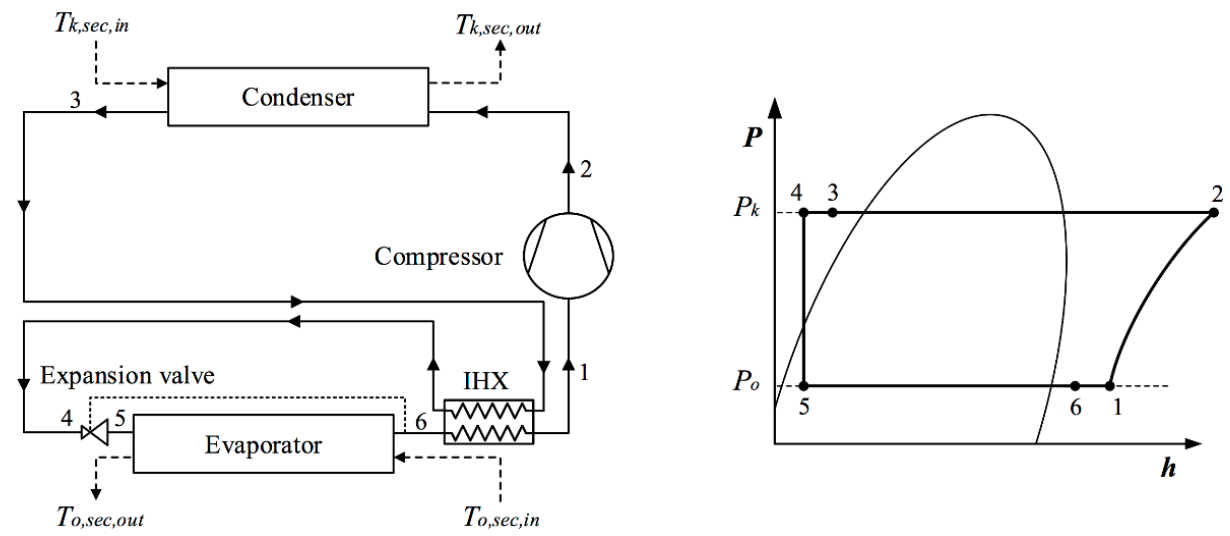

(b)

Fig.3. Schematic and P-h diagram of single-stages configurations: a) single-stage cycle and b) singlestage cycle with IHX.

The heat absorbed by the evaporator $\left(\dot{Q}_{o}\right)$ is considered as input of the model, and a constant value of $100 \mathrm{~kW}$ has been considered. In order to analyse different high-temperature applications and due to the variety of low-grade waste heat sources, different condensing and evaporating (related 
to the low-grade waste heat temperature) temperatures are combined to simulate the typical working conditions and analyse the system performance

Firstly, the evaporating temperature is varied from 45 to $75^{\circ} \mathrm{C}$, and the condensing temperature is set at $145^{\circ} \mathrm{C}$ to consider the limitation of the critical temperature of HFC-245fa $\left(153.86{ }^{\circ} \mathrm{C}\right)$. Secondly, the evaporating temperature is set at the intermediate value of $60{ }^{\circ} \mathrm{C}$ whereas the condensing temperature is varied from 115 to $145{ }^{\circ} \mathrm{C}$. Moreover, the sub-cooling degree is assumed to be $10 \mathrm{~K}$, and the superheat degree is considered to be $15 \mathrm{~K}$.

The refrigerant thermodynamic properties have been evaluated using the software REFPROP Version 10 [28] and the model has been developed using the software Engineering Equation Solver (EES) [35]. Moreover, an isenthalpic process is considered at the expansion valve and heat transfer to the surroundings and pressure drops are neglected.

The isentropic and volumetric efficiencies of the compressors are calculated using Pierre's correlations for "good" reciprocating compressors [36]. Compressor volumetric efficiency, $\eta_{v o l}$, is obtained from Eq. (1).

$$
\eta_{v o l}=k_{1} \cdot\left(1+k_{s} \cdot \frac{t_{2 k}-18}{100}\right) \cdot \exp \left(k_{2} \cdot \frac{p_{1}}{p_{2}}\right)
$$

$t_{2 k}$ is the inlet temperature to the compressor and $p_{1} / p_{2}$ is the pressure ratio. The remaining symbols $k_{1}, k_{s}$ and $k_{2}$ are constants and, the values of these are 1.04, 0.15 , and -0.07 , respectively. Then, isentropic efficiency, $\eta_{i s}$, is calculated using Eq. (2).

$$
\left(\frac{\eta_{v o l}}{\eta_{i s}}\right)=\left(1+k_{e} \cdot \frac{t_{2 k}-18}{100}\right) \cdot \exp \left(a \cdot \frac{T_{1}}{T_{2}}+b\right)
$$

$T_{1} / T_{2}$ is the ratio of the condensation and evaporation absolute temperatures (in Kelvin) corresponding to the discharge and the suction compressor pressure. The constants $k_{e}, a$ and $b$ are $-0.1,-2.40$ and 2.88 , respectively, and are taken from the literature [36]. The electromechanical efficiency, $\eta_{e m}$, is assumed to be 0.95 .

The refrigerant mass flow rate for all system configurations is calculated using Eq. (3).

$$
\dot{m}=\frac{\dot{Q}_{o}}{\left(h_{o, \text { out }}-h_{o, \text { in }}\right)}
$$

The required volumetric flow rate at the compressor suction, $\dot{V}_{s u c}$, is obtained from the mass flow rate, the suction density and the volumetric efficiency, Eq. (4).

$$
\dot{V}_{\text {suc }}=\frac{\dot{m}}{\eta_{v o l} \rho_{\text {suc }}}
$$

The maximum discharge temperature, $T_{\text {disc }}$, is limited to $175^{\circ} \mathrm{C}$ to preserve the thermal stability between the refrigerants and POE lubricants [26,30,34]. For the same reason, the IHX effectiveness $\left(\varepsilon_{\text {IHX }}\right)$ is limited. Fig. 6a shows that HCFO-1233zd(E) achieves the highest discharge temperatures of the refrigerants analysed, and the maximum IHX effectiveness for all the simulations is fixed at 0.3 to maintain the discharge temperature below the limit in each operation conditions and refrigerants analysed. The vapour suction temperature is calculated using Eq. (5). 


$$
\varepsilon_{\mathrm{IHX}}=\frac{h_{\text {suc }}-h_{o, \text { out }}}{h_{k, \text { out }}-h_{o, \text { out }}}
$$

The electric power consumption of the compressor, $\dot{W}_{C}$, is expressed in Eq. (6) as the product of the mass flow rate and the isentropic enthalpy difference at the compressor divided by the isentropic and electromechanical efficiencies.

$$
\dot{\mathrm{W}}_{\mathrm{C}}=\frac{\dot{m} \Delta h_{i s, c}}{\eta_{i s} \eta_{e m}}
$$

The heating capacity, $\dot{\mathrm{Q}}_{\mathrm{k}}$, is calculated using the product of the mass flow rate and the enthalpy difference at the condenser, Eq. (7).

$$
\dot{\mathrm{Q}}_{\mathrm{k}}=\dot{m}\left(h_{k, \text { in }}-h_{k, \text { out }}\right)
$$

To compare correctly the influence of the volumetric flow rate at the compressor suction and the heating capacity, the volumetric heating capacity (VHC) is calculated using Eq. (8).

$$
V H C=\frac{\dot{\mathrm{Q}}_{\mathrm{k}}}{\dot{V}_{\text {suc }}}
$$

Finally, the Coefficient of Performance, COP, is calculated from the heating capacity and the compressor electric power consumption, using Eq. (9).

$$
\operatorname{COP}=\frac{\dot{\mathrm{Q}}_{\mathrm{k}}}{\dot{\mathrm{W}}_{\mathrm{C}}}
$$

\section{Superheat mapping and Internal Heat Exchanger (IHX) analysis}

The positive slope of the saturated vapour curves $(\mathrm{dT} / \mathrm{ds}>0)$ in the analysed refrigerants makes necessary a particular superheating control to ensure a dry compression and prevent compressor damage. For this reason, the minimum superheat degree has been calculated for each possible combination of refrigerant and operating condition. Then, a sensitivity analysis of the IHX effectiveness has been performed to study its influence in the main operating parameters.

\subsection{Minimum superheat required}

Apart from the simulation analysis explained previously, a minimum superheat requirement analysis has been carried out at different discharge and suction pressures to facilitate the utilisation of these refrigerants in real installations (Fig. 4). This mapping has been done due to the lack of information available about the minimum superheat degree required to these refrigerants.

The highest superheat required for HFC-245fa is $5.4 \mathrm{~K}$, operating at relatively low discharge and suction pressures (0.40 and 1.9 MPa, respectively), as shown in Fig. 4a. Nevertheless, as the discharge and suction pressures increase, the required superheat decreases down to zero. The suction pressure variation is less significant. HCFO-1233zd(E) exhibits a mapping comparable to HFC-245fa but requires slightly higher minimum superheat, as shows Fig. 4b. Hence, the highest value of superheat required for $\mathrm{HCFO}-1233 \mathrm{zd}(\mathrm{E})$ is $7.1 \mathrm{~K}$ but operating at lower suction pressure and higher discharge pressure than HFC-245fa. 
The mapping presented in Fig. $4 \mathrm{c}$ for HCFO-1224yd(Z) is different from the previous refrigerants analysed. In this case, the highest superheat required, $4.4 \mathrm{~K}$, occurs at intermediate suction and discharge pressures of 0.42 and $1.9 \mathrm{MPa}$, being this value lower than that obtained for HFC-245fa. In contrast, $\mathrm{HCFO}-1224 \mathrm{yd}(\mathrm{Z})$ requires the minimum superheat operating at low suction pressures whereas HFC-245fa and HCFO-1233zd(E) show this minimum at high suction pressures. However, operating at high suction pressure reduces the minimum superheat required.

Finally, HFO-1336mzz(Z) presents a significantly different mapping to the rest of working fluids, highlighting the significant increase of the minimum superheat requirement, as shows Fig. $4 \mathrm{~d}$. The highest superheat required is $19.2 \mathrm{~K}$, operating at the intermediate suction pressure of 0.25 MPa but at the highest discharge pressure, $1.8 \mathrm{MPa}$, and hence at different conditions. Similarly, the superheat required decreases as the suction pressure increases contrary to the other refrigerants, which requires the minimum values at high suction pressures. The isentropic curve slope for HFO-1336mzz(Z) is higher than for the other refrigerants, requiring a higher minimum superheat degree than the other alternatives.

Therefore, HCFO-1233zd(E) and HCFO-1224yd(Z) operate similar to HFC-245fa and have the minimum superheat requirement at higher heat productions temperatures, whereas HFO$1336 \mathrm{mzz}(\mathrm{Z})$ at lower ones. Besides, moderate waste heat temperatures, producing evaporation temperatures between 50 and $60^{\circ} \mathrm{C}$, require the highest superheat degree.

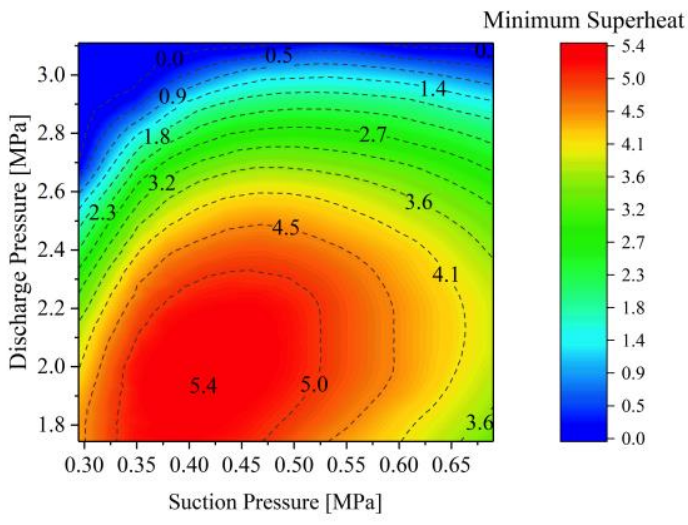

(a)

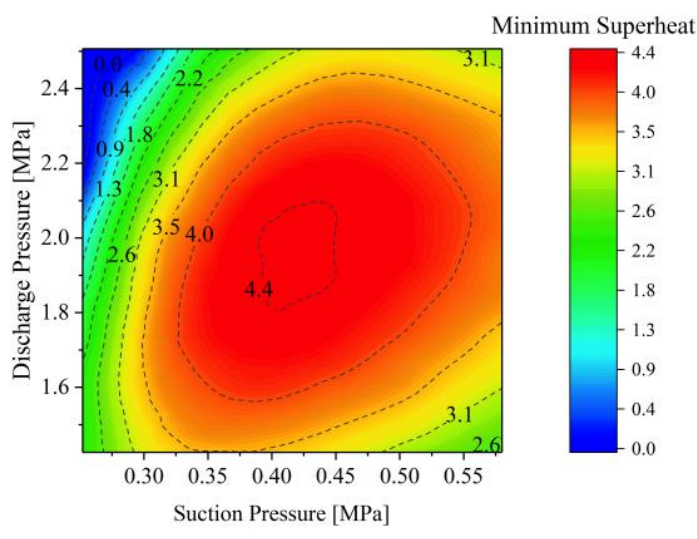

(c)

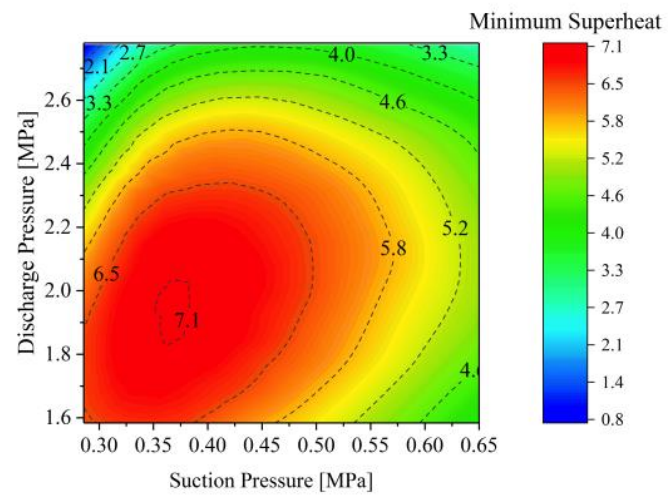

(b)

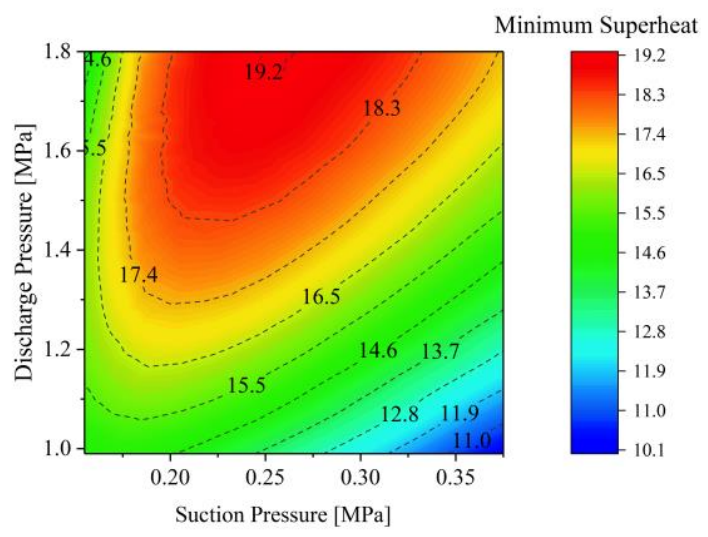

(d)

Fig. 4. Mapping of the minimum superheating required for: a) HFC-245fa, b) HCFO1233zd(E), c) HCFO-1224yd(Z) and d) HFO-1336mzz(Z). 


\subsection{Influence of Internal Heat Exchanger (IHX)}

The addition of an IHX to a single-stage vapour compression cycle could improve the system performance, volumetric heating capacity and ensure a dry compression. Nevertheless, the system response to its introduction depends on the refrigerant and the IHX effectiveness $\left(\varepsilon_{I H X}\right)$, and there is the possibility that the system performance can be deteriorated. Consequently, a sensitivity analysis of the IHX effectiveness becomes interesting. Fig. 5 shows the relative difference between the configuration with and without IHX adoption at varying IHX effectiveness, for all the refrigerants and selected operating parameters.

As shown in Fig. 5a, the discharge temperature significantly increases with the IHX effectiveness. All the low GWP alternatives show higher discharge temperature increments than HFC-245fa, becoming higher as the IHX effectiveness increases. While HCFO-1224yd(Z) and HFO$1336 \mathrm{mzz}(\mathrm{Z})$ present slightly lower discharge temperature values than HFC-245fa, HCFO$1223 \mathrm{zd}(\mathrm{E})$ shows significanlty higher discharge temperature values. Looking at the specific heat ratio, $\mathrm{HCFO}-1224 \mathrm{yd}(\mathrm{Z})$ and $\mathrm{HFO}-1336 \mathrm{mzz}(\mathrm{Z})$ have lower values for this parameter than the reference fluid, whereas HCFO-1233zd(E) has higher values. Thus, this specific heat ratio difference is the main reason for the variation in discharge temperature. These increases of discharge temperature become a critical operating parameter to be considered, especially in hightemperature applications, for the components and installation limitations.

As Fig. 5b shows, the COP increases up to $43 \%$ at high IHX effectiveness. Compared to HFC245fa, HFO-1336mzz(Z) achieves lower COP increment than HFC-245fa, followed by HCFO$1224 \mathrm{yd}(\mathrm{Z})$. On the other hand, HCFO-1233zd(E) has a significant increment of the system performance as the IHX effectiveness increases up to $8 \%$ compared to HFC-245fa with the highest IHX effectiveness.

Attending to Fig. 5c and 5d, although the heating capacity decreases as the IHX effectiveness increases, the volumetric heating capacity increases due to the more significant volumetric flow rate reduction in the compressor suction than that in the heating capacity. In this case, HFO$1336 \mathrm{mzz}(\mathrm{Z})$ shows slightly lower values than HFC-245fa. However, HCFO-1224yd(Z) and HCFO-1233zd(E) tend to be situated above HFC-245fa. Therefore, the HCFO refrigerants would provide better heating capacity with IHX than the other alternative refrigerant.

Finally, Fig. 5e and 5f show the variation of superheat and sub-cooling with an increment of IHX effectiveness, respectively. As it was expected, superheat and sub-cooling increase at higher IHX effectiveness. The sub-cooling improvement of HCFO-1233zd(E) compared to HFC-245fa can be considered higher whereas the other refrigerants have similar behaviour to the reference fluid. The mass flow rate difference between HCFO-1233zd(E) and the other refrigerant would be the main responsible for this variation. The analysis shows that lower IHX effectiveness values can achieve significant increments of superheat and sub-cooling, and hence ensure the dry compression (particularly for HFO-1336mzz(Z)).

All the refrigerants present a similar response to the use of IHX. Nevertheless, HCFO-1233zd(E) shows higher performance improvements and lower heating capacity reduction than the rest alternatives. HCFO-1224yd(Z) and HFO-1336mzz(Z) have close similar values than HFC-245fa. Nevertheless, the discharge temperature of HCFO-1233zd(E) is considerably higher than the other alternatives, which show a lower discharge temperature than HFC-245fa with the use of IHX. 


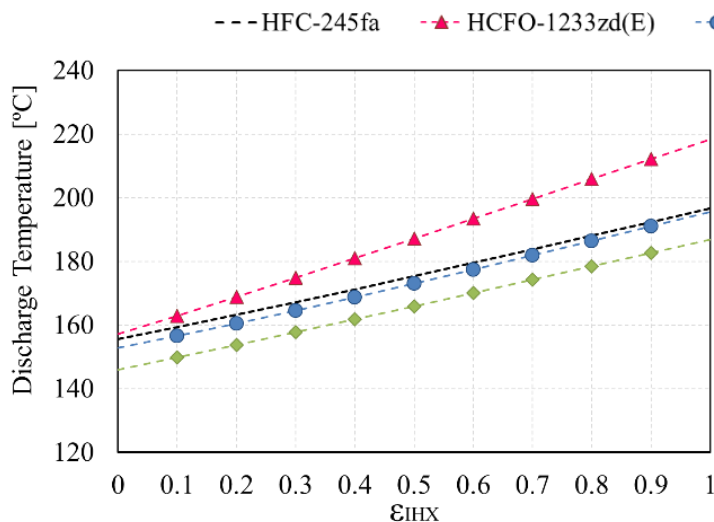

(a)

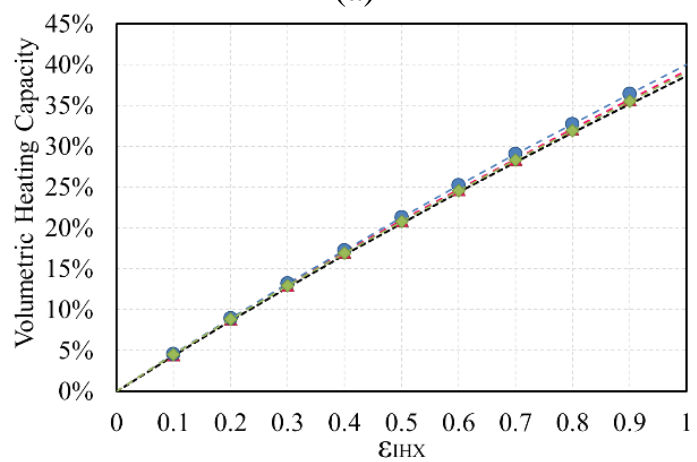

(c)

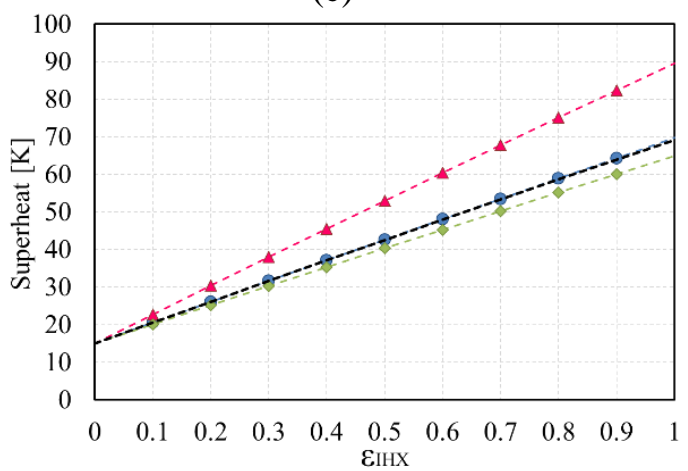

(e)

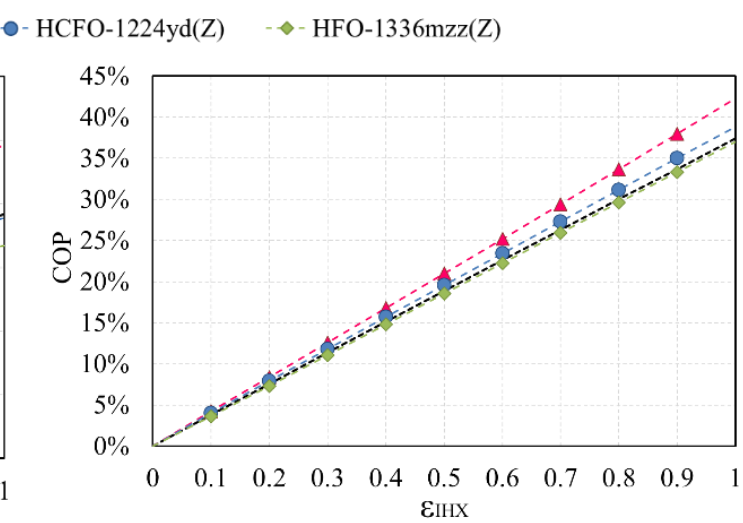

(b)

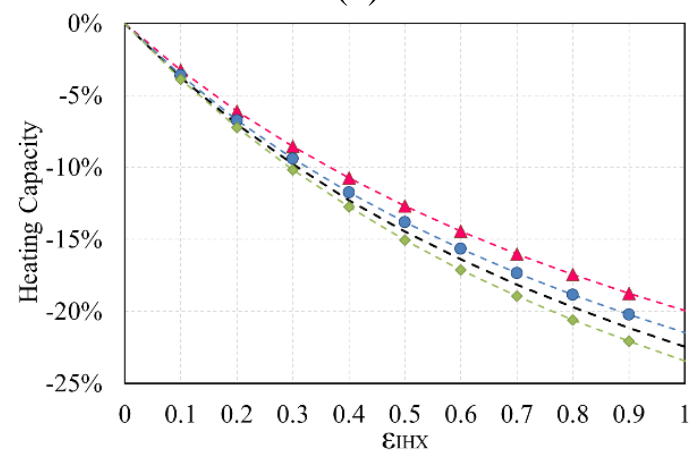

(d)

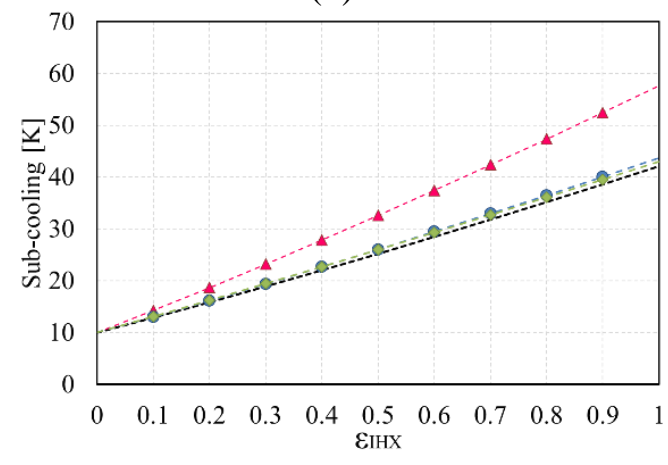

(f)

Fig. 5. Influence the effectiveness of the IHX in: a) Discharge Temperature, b) COP, c) Volumetric Heating Capacity, d) Heating Capacity, e) Superheat and f) Sub-cooling.

\section{Simulations analysis results}

This section analyses the results obtained in the simulations using HFO-1336mzz(Z), HCFO1233zd(E) and HCFO-1224yd(Z) as low GWP alternatives to HFC-245fa, showing the variation of the main energy performance parameters: heating capacity, compressor power consumption and COP; along with other parameters of interest as compressor volumetric flow and discharge temperature. Both configurations simulation results are shown as relative deviations to that of HFC-245fa used in the architecture without IHX, to analyse the influence of the low GWP alternatives retrofit with IHX adoption.

\subsection{Suction volumetric flow and mass flow rate}

When the condensing temperature is fixed to $145^{\circ} \mathrm{C}$, HFO-1336mzz(Z) shows the highest increment of relative suction volumetric flow difference up to $95 \%$, as shown in Fig. 6a.. In contrast, HCFO-1224yd(Z) and HCFO-1233zd(E) present an $8 \%$ variation of the suction volumetric flow compared to HFC-245fa. The addition of the IHX reduces the suction volumetric 
flow around $20 \%$ in all the refrigerants, showing similar response with the evaporating temperature as shown in Fig. 6 b.

When the evaporating temperature is set constant to $60^{\circ} \mathrm{C}$, the variable response of this parameter becomes lower than the previous situation. In this case, $\mathrm{HFO}-1336 \mathrm{mzz}(\mathrm{Z})$ has a constant relative increment of $80 \%$ whereas the other refrigerants remain with no significant variations, as shown in Fig. 6c. Integrating the IHX, HFO-1336mzz(Z) reduces the relative difference significantly, from $80 \%$ to $45 \%$, whereas HCFO-1233zd(E) and HCFO-1224yd(Z) show a relative reduction difference up to $20 \%$ in high condensation temperatures as shown Fig. $6 \mathrm{~d}$.

Therefore, HCFO-1233zd(E) and HCFO-1224yd(Z) could be working with the existing compressor as possible drop-in replacements for HFC-245fa whereas HFO-1336mzz(Z) requires higher compressor and installation size than HFC-245fa.

$\star$ HCFO-1233zd(E) $\bullet \cdot$ HCFO-1224yd(Z) $\cdot$ HFO-1336mzz(Z)

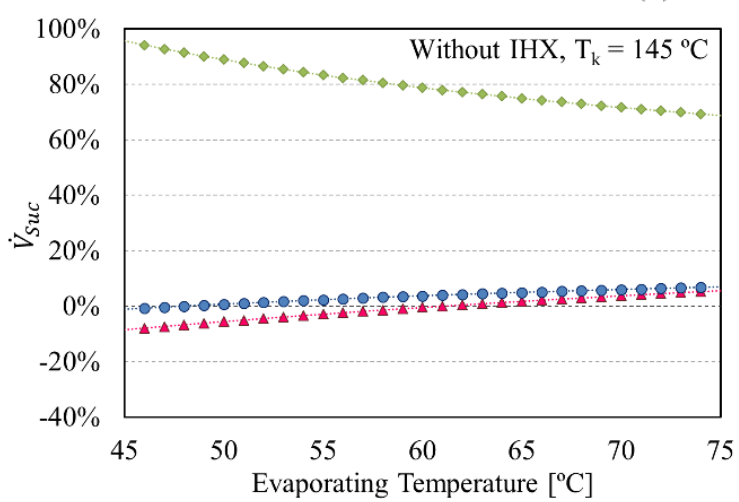

(a)

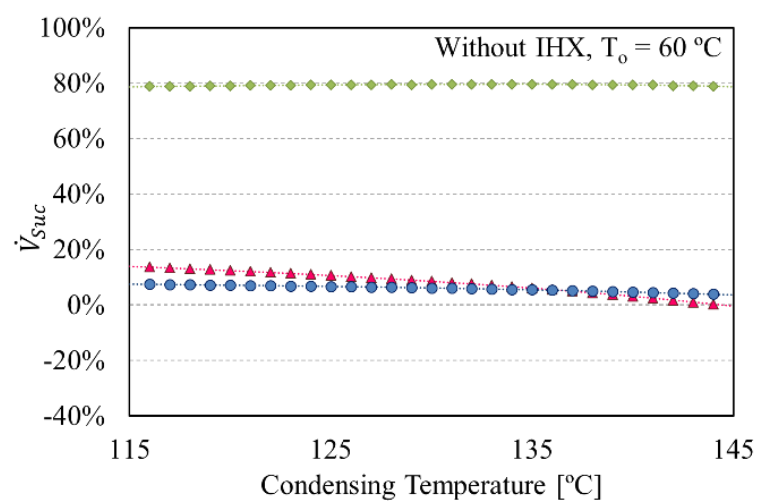

(c)

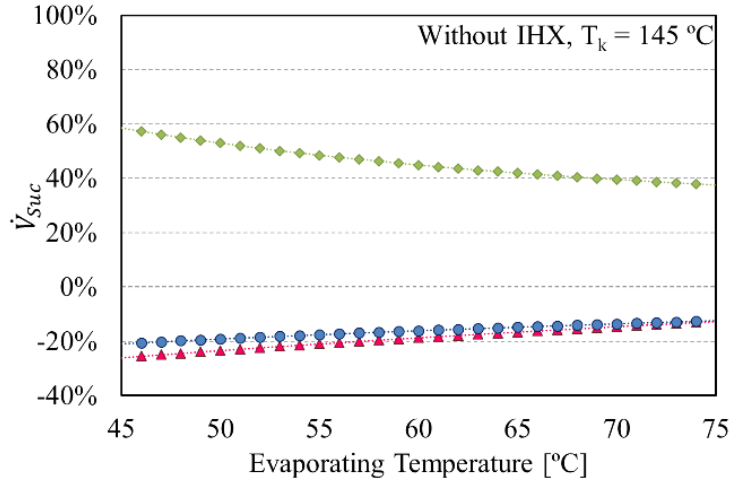

(b)

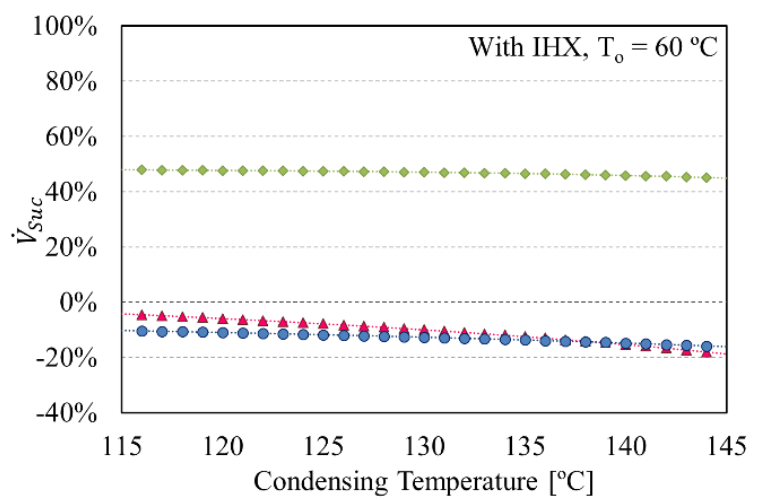

(d)

Fig. 6. Relative differences of the suction volumetric flow varying the condensing temperature (a) without IHX, (b) with IHX; and the evaporating temperature (c) without IHX and (d) with IHX.

Looking at the mass flow rate difference, HCFO-1233zd(E) presents lower values of this parameter in all the operating conditions analysed. The reduction of this parameter ranges between $5 \%$ and $20 \%$ without the IHX and between $12 \%$ and $38 \%$ with it. The other candidates show a slight increase in mass flow rate without IHX, whereas this parameter is comparable or lower than HFC-245fa with the use of IHX, as shown in Fig. 7. With a constant cooling capacity, higher values of latent heat of vaporisation would give lower mass flow rates. Thus, the higher latent heat of vaporisation of HCFO-1223zd(E) compared with the other refrigerants is the primary responsible of this difference with the other refrigerants. This variation of mass flow rate becomes essential for the understanding of the following parameter analysis. 


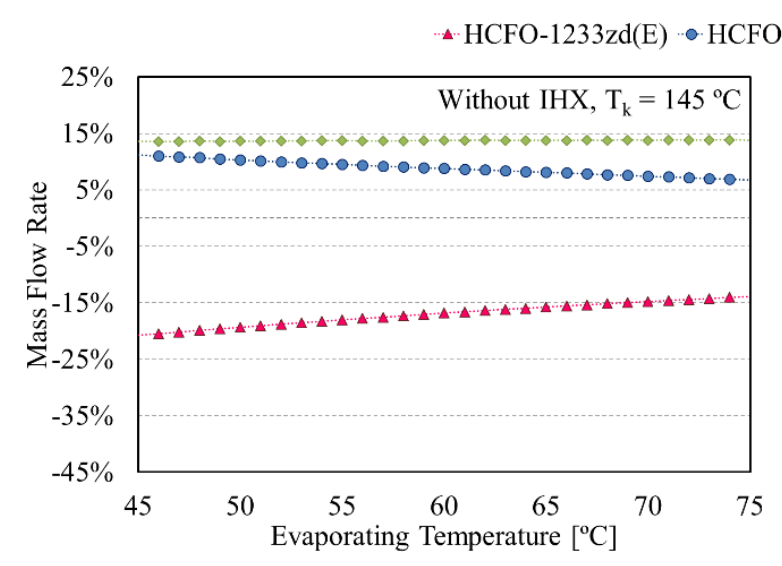

(a)

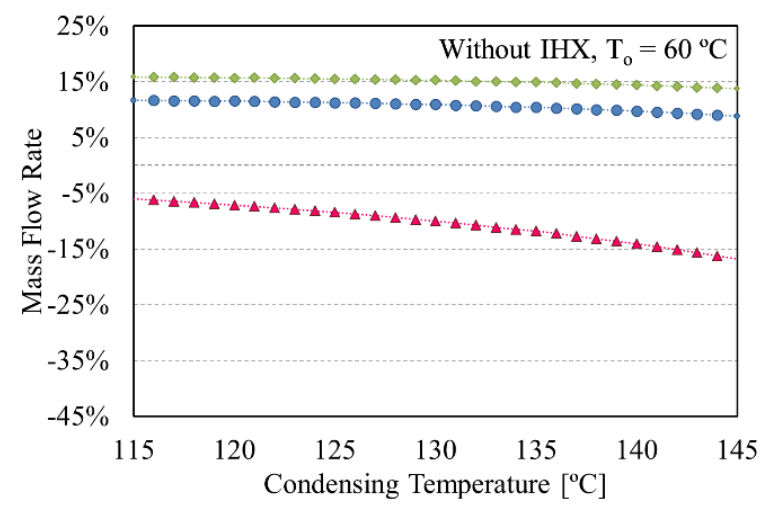

(c)

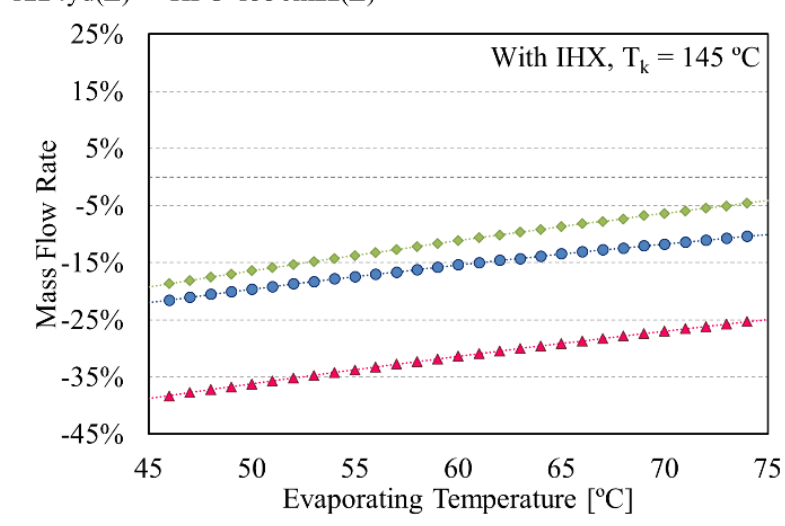

(b)

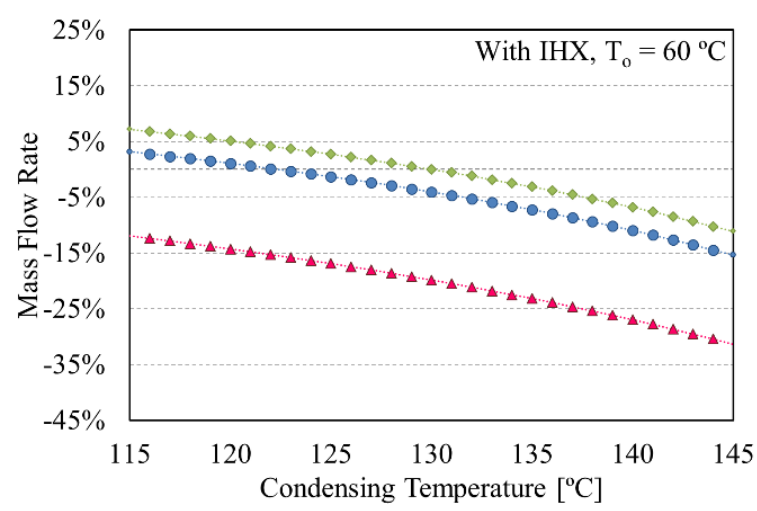

(d)

Fig. 7. Relative differences of the mass flow rate varying the condensing temperature (a) without

IHX, (b) with IHX; and the evaporating temperature (c) without IHX and (d) with IHX.

\subsection{Discharge temperature}

No significant relative variation in the discharge temperature is observed using HCFO-1233zd(E) and HCFO-1224yd(Z) when the system operates without IHX, as shown Fig 8a and Fig. 8b. Nevertheless, HFO-1336mzz(Z) presents a 5\% relative reduction. According to the IHX analyses previously performed, the addition of IHX increases the relative difference of the discharge temperature for $\mathrm{HCFO}-1233 \mathrm{zd}(\mathrm{E})$ and $\mathrm{HCFO}-1224 \mathrm{yd}(\mathrm{Z})$ up to $15 \%$ and $10 \%$, respectively, operating at low evaporation temperatures, as shown in Fig. 8b. As for the condensing temperature increase with IHX, the relative difference of all refrigerants decreases as shown Fig. 7c and 7d. This is caused by the lower critical temperature of HFC-245fa compared with the other working fluids.

As mentioned before, these discharge temperature differences are caused by a variation of the specific heat ratio in each refrigerant. HCFO-1233zd(E), with higher values of specific heat ratio, shows the highest discharge temperature relative increase. This fact should be considered in possible drop-in replacements for HFC-245fa. 
$\star$ HCFO-1233zd(E) $\bullet$ HCFO-1224yd(Z) $\bullet$ HFO-1336mzz(Z)

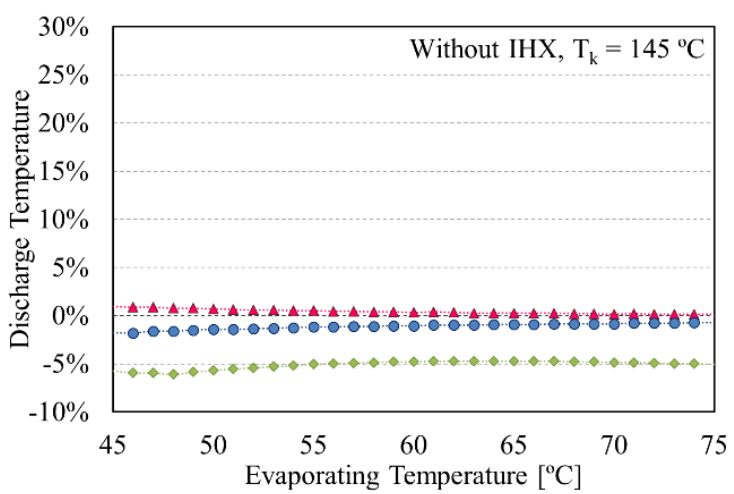

(a)

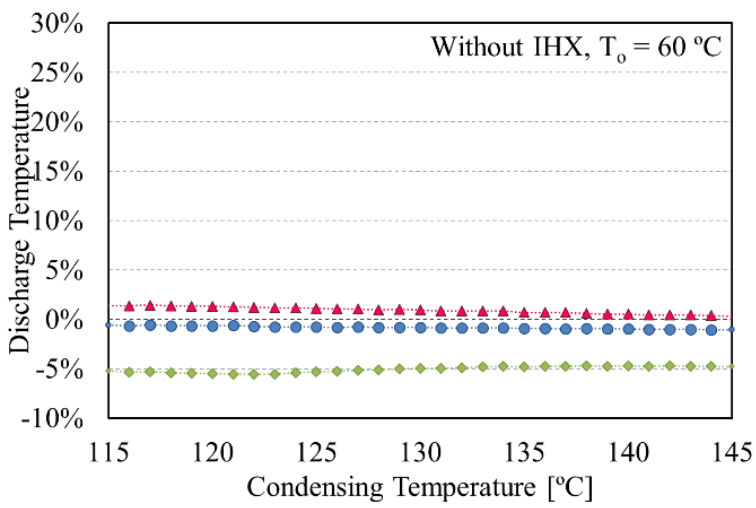

(c)

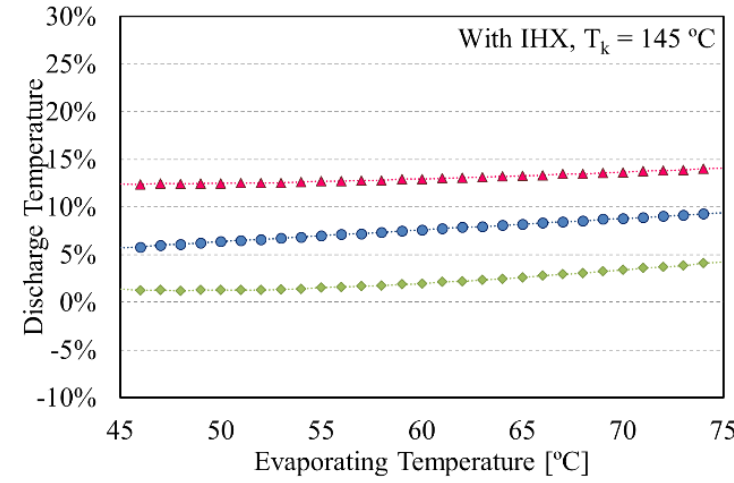

(b)

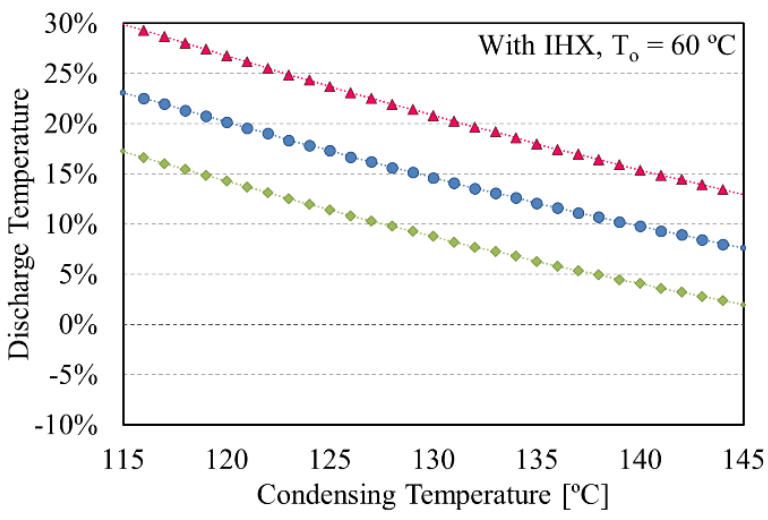

(d)

Fig. 8. Relative differences of the discharge temperature varying the condensing temperature (a) without IHX, (b) with IHX; and the evaporating temperature (c) without IHX and (d) with IHX

\subsection{Heating capacity}

The relative variation of the heating capacity with the evaporating and condensing temperatures, with and without IHX is shown in Fig. 9. This parameter is a consequence of the latent heat of condensation and the mass flow rate, presented before. HFO-1336mzz(Z) and HCFO-1224yd(Z) present a $4 \%$ relative decrease with a constant condensing temperature of $145^{\circ} \mathrm{C}$, as shown in Fig. 9a. Besides, HCFO-1233zd(E) shows an $11 \%$ heating capacity reduction compared to HFC$245 \mathrm{fa}$, which becomes lower as the evaporating temperature increases. The IHX adoption reduces the relative heating capacity difference of the considered low GWP alternatives significantly. When lower evaporating temperatures are considered, the relative difference of the heating capacity increases with the evaporating temperatures, as shown in Fig. 9b. The reduction of heating capacity for HFO-1336mzz(Z) and HCFO-1224yd(Z) is more sensitive to the adoption of IHX than HCFO-1233zd(E), as mentioned above in section 4.2.

Setting the evaporating temperature at $60^{\circ} \mathrm{C}$ and varying the condensing temperature, minimum relative heating capacity differences are appreciated for $\mathrm{HFO}-1336 \mathrm{mzz}(\mathrm{Z})$ and $\mathrm{HCFO}-1224 \mathrm{yd}(\mathrm{Z})$, as shown in Fig. 9c. Nevertheless, HCFO-1233zd(E) presents a $6 \%$ relative difference at high condensation temperatures. Adding the IHX, all the alternatives reduce the heating capacity, compared to the reference, as the condensing temperature increases, from $2 \%$ to $10 \%$ approximately, as shown in Fig. 9d.

Due to the mass flow rate difference of the alternatives compared to HFC-245fa in most of the operating points, the heating capacity becomes lower. In some refrigerants, this heating reduction 
could be compensated with a higher latent heat of condensation, providing better heating capacity than the other refrigerants.

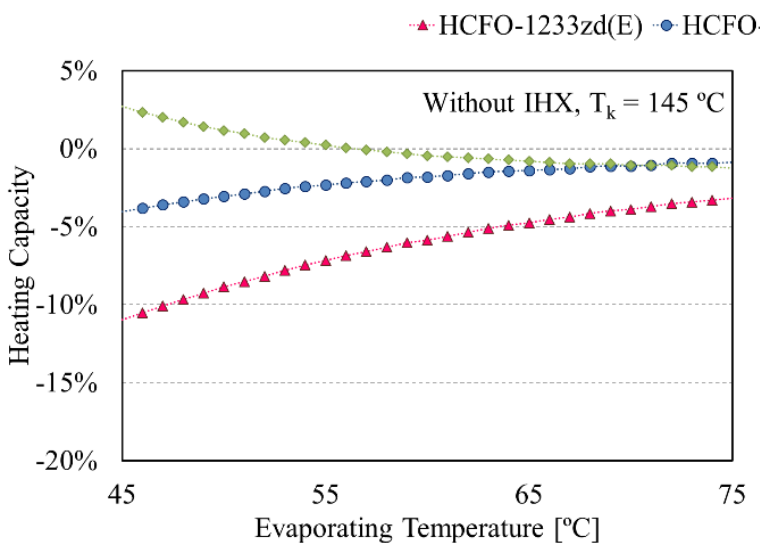

(a)

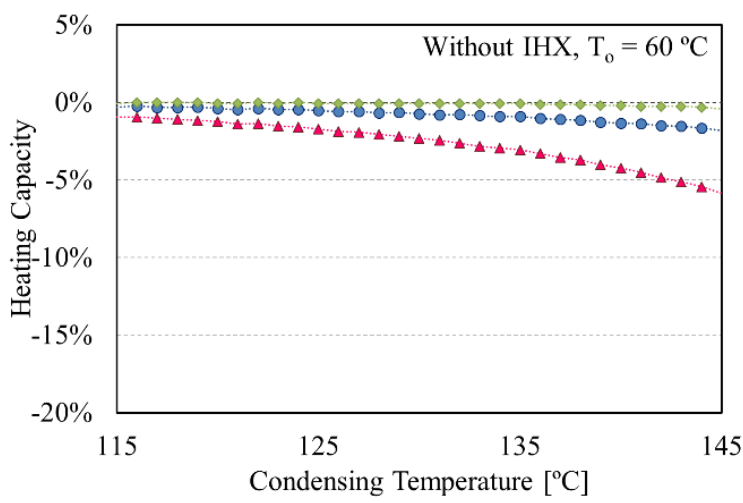

(c)

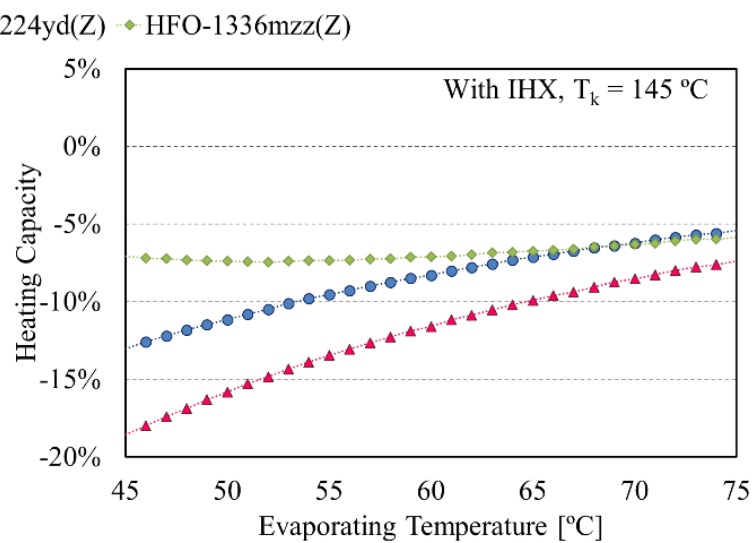

(b)

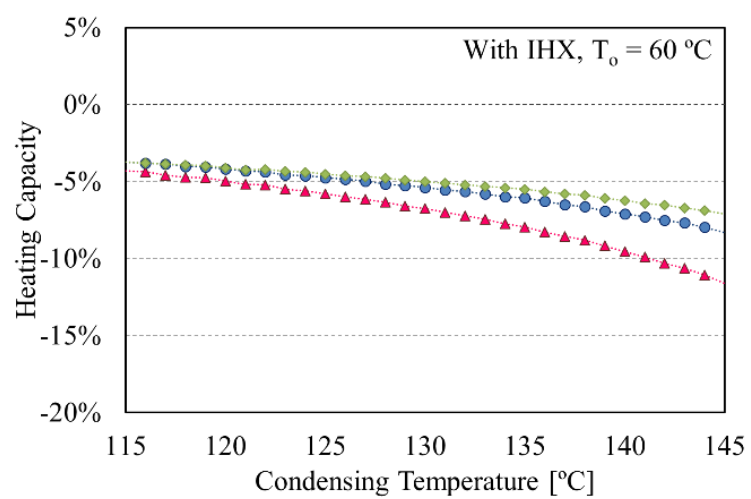

(d)

Fig. 9. Relative differences of the heating capacity varying the condensing temperature (a) without IHX, (b) with IHX; and the evaporating temperature (c) without IHX and (d) with IHX.

\subsection{Compressor power consumption}

The compressor power consumption is proportional to the mass flow rate and the isentropic lines slope of each refrigerant. As each refrigerant has a similar slope, the mass flow rate variation would be the main factor influencing the compressor power consumption.

Fig. 10 shows the relative compressor power consumption difference in comparison to the reference fluid. In this case, with a constant condensing temperature of $145^{\circ} \mathrm{C}, \mathrm{HCFO}-1233 \mathrm{zd}(\mathrm{E})$ presents the highest reduction, going from $12 \%$ to $20 \%$ as the evaporating temperature increases. This is caused due to the mass flow rate reduction of HCFO-1233zd(E) compared to the reference HFC-245fa. Considering low evaporating temperatures, HFO-1336mzz(Z) shows an increase of the relative difference whereas HCFO-1224yd(Z) reduces it. Nevertheless, the HCFO-1224yd(Z) trend increases for higher evaporating temperature while the HFO-1336mzz(Z) trend decreases, becoming slightly above that of $\mathrm{HCFO}-1224 \mathrm{yd}(\mathrm{Z})$ at high evaporating temperatures, as shown Fig. 10a. All the refrigerants reduce the relative compressor power consumption difference when the IHX integration is considered. Fig. 10b shows that this reduction becomes more significant for $\mathrm{HCFO}-1233 \mathrm{zd}(\mathrm{E})$ and $\mathrm{HCFO}-1224 \mathrm{yd}(\mathrm{Z})$ at low evaporating temperatures, $35 \%$ and $25 \%$, respectively. However, as the evaporating temperature increases, HCFO-1233zd(E) and HCFO$1224 \mathrm{yd}(\mathrm{Z})$ reduce the relative difference around $8 \%$, whereas for HFO- $1336 \mathrm{mzz}(\mathrm{Z})$ is between $12-22 \%$, as the evaporating temperature increase. 
At a constant evaporating temperature of $60{ }^{\circ} \mathrm{C}$, Fig. 10c shows that HFO-1336mzz(Z) and HCFO-1224yd(Z) present no significant variation of the relative difference whereas HCFO$1233 \mathrm{zd}(\mathrm{E})$ decrease this relative compressor power consumption difference from $5 \%$ to $17 \%$ as the condensing temperature increase. Finally, Fig. 10d illustrates a significant reduction of the relative difference around $20 \%$ for each refrigerant with the use of IHX. A similar evolution of the power consumption than without IHX is observed as the condensing temperature increase.

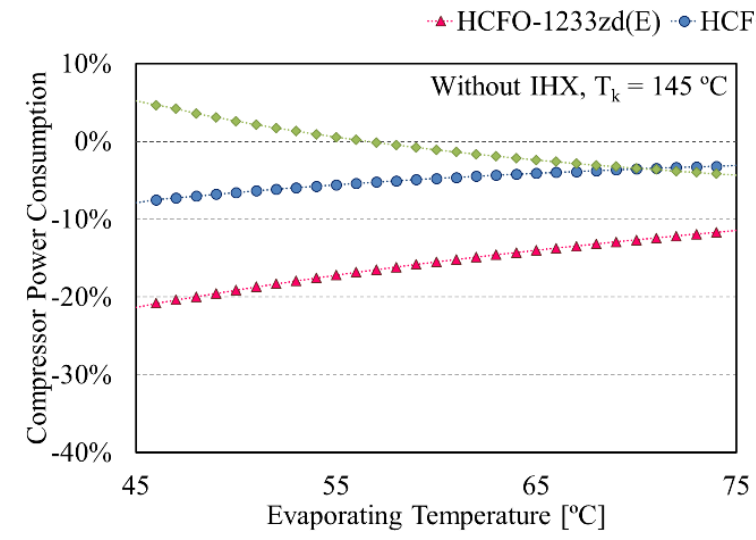

(a)

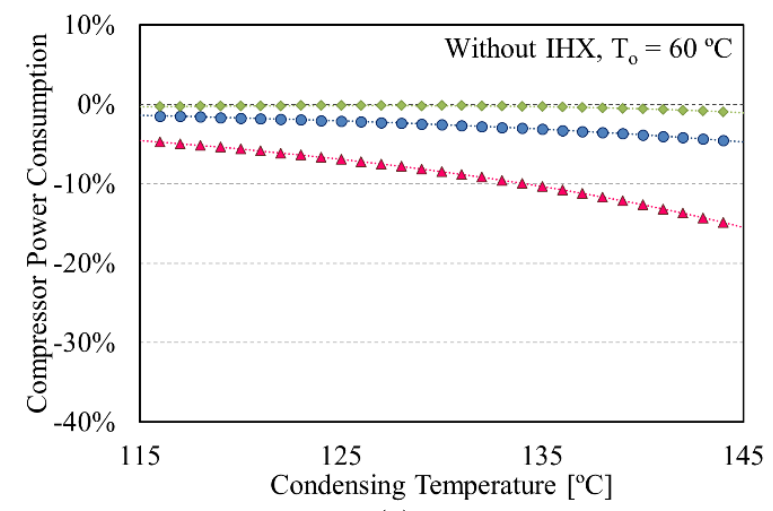

(c)

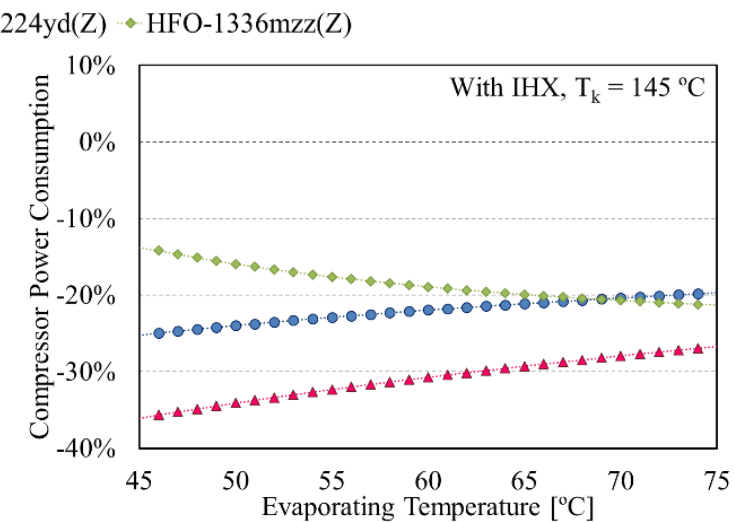

(b)

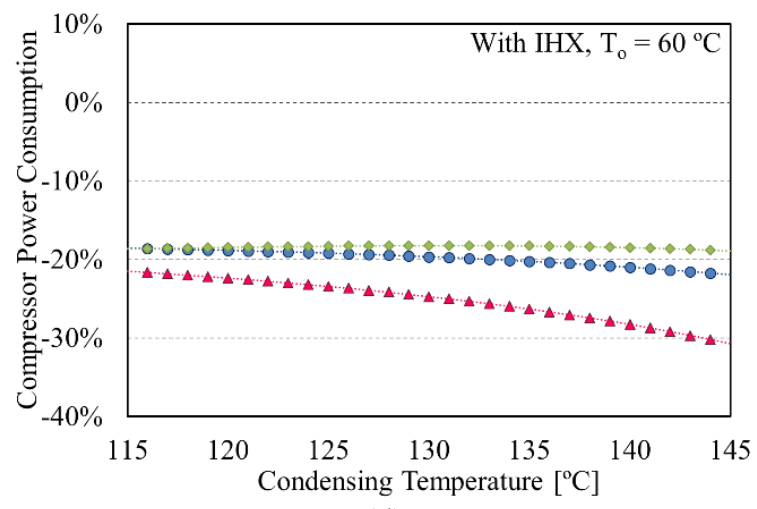

(d)

Fig. 10. Relative differences of the compressor power consumption varying the condensing temperature (a) without IHX, (b) with IHX; and the evaporating temperature (c) without IHX and (d) with IHX.

\subsection{Coefficient of Performance (COP)}

The relative differences in the COP presented in Fig. 11 show that each alternative refrigerant has the same or even more performance than the reference HFC-245fa. HCFO-1233zd(E) presents the highest values of improvement followed by the HCFO-1224yd(Z). Varying the evaporation temperature without IHX, the variation of HCFO-1233zd(E) goes from $10 \%$ to $14 \%$ as the evaporating temperature increase. In contrast, HCFO-1224yd(Z) and HFO-1336mzz(Z) have a variation below 5\%, as shown in Fig. 11a. The addition of IHX increases the relative difference from $14 \%$ to $27 \%$ in low evaporating temperatures for HCFO-1233zd(E), achieving similar values at the highest condition. Similar behaviour is observed for HCFO-1233zd(E), with $10 \%$ lower COP difference than HCFO-1233zd(E). Finally, HFO-1336mzz(Z) shows 7\% increment of relative difference of COP. However, instead of remaining constant for an increment of the evaporating temperature, this relative difference increases. At the highest evaporating temperatures, HFO-1336mzz(Z) presents higher relative difference of COP than HCFO$1224 \mathrm{yd}(\mathrm{Z})$. 
With a constant evaporating temperature of $60^{\circ} \mathrm{C}$, the variation of condensing temperature shows lower improvement in the relative COP difference than the previous case. Whereas HFO$1336 \mathrm{mzz}(\mathrm{Z})$ and $\mathrm{HCFO}-1224 \mathrm{yd}(\mathrm{Z})$ present no significant variations, HCFO-1233zd(E) improves this relative difference from $4 \%$ to $11 \%$ as the condensing temperature increases, as shown Fig. 11c. Looking to the use of IHX in this conditions, each refrigerant shows similar evolution than without IHX, but a 17\% relative increase of COP is observed, as shown Fig. 11d.

Therefore, HFCO-1233zd(E) presents a significant energy performance improvement compared to HFC-245fa with and without IHX, being higher with IHX is integrated. Otherwise, HCFO$1224 \mathrm{yd}(\mathrm{Z})$ and HFO-1336mzz(Z) have comparable COP to HFC-245fa operating without IHX whereas a significant COP increment could be appreciated with IHX. Finally, HFO-1336mzz(Z) shows performance improvements when the evaporating temperature increases, and therefore, this refrigerant would be appropriate for high source temperatures.

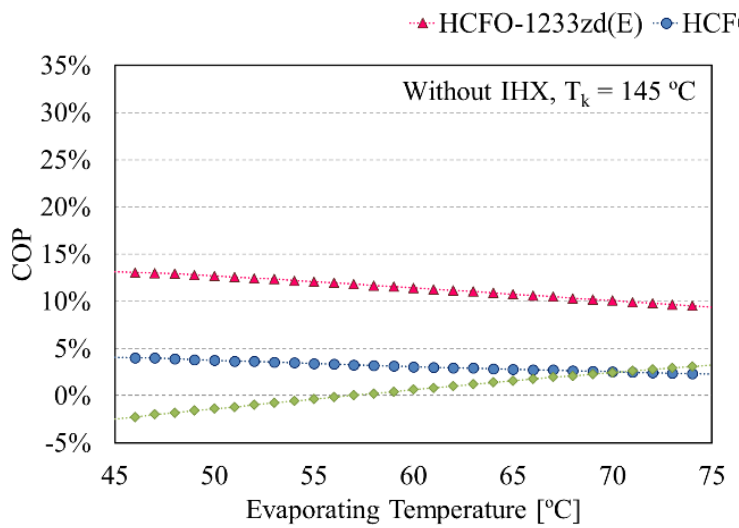

(a)

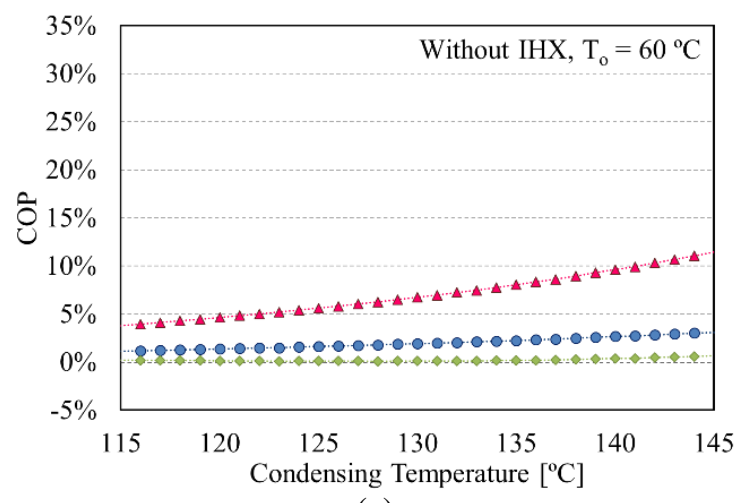

(c)

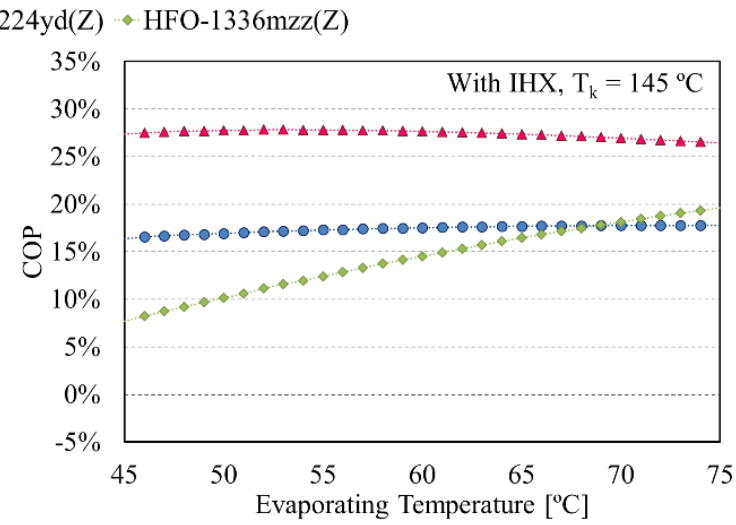

(b)

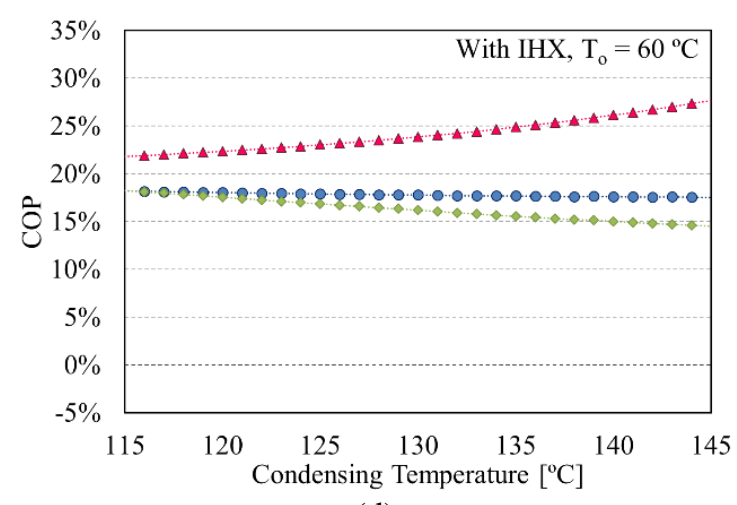

(d)

Fig. 11. Relative differences of the COP varying the condensing temperature (a) without IHX, (b) with IHX; and the evaporating temperature (c) without IHX and (d) with IHX.

\subsection{Heat transfer analysis}

The thermodynamic and transport properties of each refrigerant influence the pressure drop and heat transfer in the heat exchangers of the system. An adequate comparison of both parameters under the same conditions provides useful information about its required size. This analysis can be carried out separating the independent terms in heat transfer and pressure drop correlations, (corresponding to the installation characteristics), and form what is called figure of merit (FOM). This method for visualising the heat transfer and pressure drop difference was used by Palm to compare several hydrocarbons refrigerants [37]. The development of the FOM equations can be consulted in this work. 
The FOM for pressure drop in a single-phase turbulent flow can be expressed as shown in Eq. (10). Hence, lower $F O M_{\Delta p}$ value explains that a lower pressure drop should be expected.

$$
F O M_{\Delta p}=\frac{\mu^{1 / 4}}{\rho h_{f g}^{7 / 4}}
$$

This FOM shows that the pressure drop is influenced not only by the viscosity, and that the latent heat of vaporisation is even more critical, because it determines the required mass flow rate for certain cooling capacity and density. In Table 3,FOM $M_{\Delta p}$ is given for liquid and vapor phase at $130^{\circ} \mathrm{C}$. For the liquid phase, HCFO-1233zd(E) and HFO-1336mzz(Z) show $20 \%$ and $12 \%$ lower values of $F_{0 M}$ compared to HFC-245fa, respectively, due to their higher latent heat of vaporization and liquid density. In contrast, the lower heat of vaporisation of the HCFO$1224 \mathrm{yd}(\mathrm{Z})$ seems the mainly responsible of the considerably higher values of $F O M_{\Delta p}$, showing that, for the same heat exchanger and heat flow, the pressure drop would be notably higher for HCFO-1224yd(Z) and lower for the other alternatives. Looking at the vapour phase, all the alternatives show higher $F O M_{\triangle p}$ than HFC-245fa, therefore, significantly higher pressure drop would be expected for the refrigerants proposed. The main responsible for this behaviour seems to be the lower vapour density of the alternatives compared with the reference fluid.

Similarly, the convective heat transfer is evaluated using the FOMs derivate from the DittusBoelter equation for single turbulent phase as show in Eq. (11).

$$
F O M_{S P H T}=\frac{k P r^{0.4}}{\left(h_{f g} \mu\right)^{0.8}}
$$

In contrast to the previous FOM, higher values of this parameter indicate better heat transfer. This parameter has been calculated for liquid and vapour phases, and the values are included in Table 3. Looking at both phases at the same time, the alternative refrigerant have lower $F O M_{S P H T}$ and, therefore, the heat transfer in single phase of the candidates would be lower than the reference fluid HFC-245fa. It seems that the lower thermal conductivity of the alternative refrigerants in liquid and vapour phase should be the main responsible of this lower heat transfer.

In vapour compression systems, heat transfer in boiling and condensation is more critical than single-phase. Thus, using Cooper's pool boiling correlation and assuming a surface roughness of $1 \mu \mathrm{m}$, the FOM presented in Eq. (12) is derived.

$$
F O M_{p b}=p_{r}^{0.12}\left(-\log _{10} p_{r}\right)^{-0.55} M^{-0.5}
$$

Similarly, high values of this parameter indicate a high pool boiling heat transfer coefficient. Looking at Table 3, HFC-245fa shows higher pool boiling heat transfer than the alternatives. The higher molecular weight and a lower reduced pressure of the other refrigerants compared to HFC245 fa would lower the pool boiling heat transfer as Eq. (12) illustrates.

In conclusion, the comparison of expected pressure drop and heat transfer performance using FOMs indicates that the alternatives proposed have a lower heat transfer compared to HFC-245fa. Among the three low GWP refrigerants discussed, HFO-1336mzz(Z) and HCFO-1233zd(E) have a lower pressure drop in a liquid phase whereas HCFO-1224yd(Z) shows higher values of this parameter. Finally, all the candidates have a higher pressure drop in the vapour phase than HFC$245 \mathrm{fa}$. The values are calculated for the temperature $130^{\circ} \mathrm{C}$, but the relation between the values is the same at $60^{\circ} \mathrm{C}$. 
Table 3 Transport properties and figures of merit at $130^{\circ} \mathrm{C}$

\begin{tabular}{|c|c|c|c|c|}
\hline Refrigerant no & HFC-245fa & HFO-1336mzz(Z) & HCFO-1233zd(E) & HCFO-1224yd(Z) \\
\hline $\begin{array}{c}\text { Liquid/Vapour } \\
\text { thermal conductivity } \\
\left(\mathrm{W} \cdot \mathrm{m}^{-1} \cdot{ }^{\circ} \mathrm{C}^{-1}\right)\end{array}$ & $55.50 / 23.38$ & $51.39 / 21.23$ & $54.59 / 21.91$ & $46.82 / 20.54$ \\
\hline $\begin{array}{c}\text { Liquid/ Vapour } \\
\text { viscosity }{ }^{\mathrm{a}}(\mu \mathrm{Pa} \cdot \mathrm{s})\end{array}$ & $94.82 / 15.33$ & $108.00 / 14.14$ & $94.35 / 14.01$ & $82.13 / 15.64$ \\
\hline $\mathrm{FOM}_{\triangle \mathrm{p}, \mathrm{l}}$ & 11.04 & 9.65 & 8.78 & 12.91 \\
\hline $\mathrm{FOM}_{\Delta \mathrm{p}, \mathrm{v}}$ & 42.1 & 61.1 & 44.5 & 52.8 \\
\hline $\mathrm{FOM}_{\mathrm{SPHT}, \mathrm{l}}$ & 2.42 & 1.92 & 2.00 & 2.37 \\
\hline FOM $_{\mathrm{SPHT}, \mathrm{v}}$ & 3.14 & 2.41 & 2.34 & 2.75 \\
\hline FOM $_{\mathrm{pb}}$ & 0.203 & 0.131 & 0.164 & 0.189 \\
\hline
\end{tabular}

\section{Guideline for the optimal refrigerant selection}

When selecting a working fluid, several parameters must be considered at the same time. Therefore, a mapping of the relative deviation of the alternative refrigerants to the baseline refrigerant for the main energetic parameters, $\mathrm{COP} / \mathrm{COP}_{\text {ref }}$ and $\mathrm{VHC} / \mathrm{VHC}_{\text {ref, have been }}$ performed to suggest the optimal refrigerant for each application.

Looking at the energetic performance, HCFO-1233zd(E) and HCFO-1224yd(Z) are comparable, providing the highest COP at low evaporating and high condensing temperatures. Nevertheless, it is expected to be reduced as the evaporating temperature increases or the condensing temperature decreases. In contrast, HFO-1336mzz(Z) has different response than the other alternatives. This refrigerant has the lowest COP with low evaporating and high condensing temperatures, but as the evaporating temperature increases, the COP of HFO-1336mzz(Z) also increases. Moreover, a variation of the condensing temperature has not practical influence on the $\mathrm{COP}$ of this refrigerant, as shown in Fig. 12a.

On the other hand, the VHC of HCFO-1233zd(E) has a similar behaviour to its COP, Fig. 12b. The high-performance zone also has closer VHC to that of HFC-245fa. Therefore, its optimal zone would be low evaporating and high condensing temperatures. Similarly, HCFO-1244yd(Z) has the same behaviour to the previous refrigerant mentioned but its VHC is comparable to HFC245fa. Therefore, a similar compressor and installation size could be used. Finally, HFO$1336 \mathrm{mzz}(\mathrm{Z})$ results in the lowest $\mathrm{VHC}$, which indicates that a higher compressor size is required to provide the same amount of heat.

In conclusion, HCFO-1233zd(E) and HCFO-1224yd(Z) would be the optimal refrigerants for low heat source temperature and high-temperature heating production applications. Moreover, these refrigerants are highly sensitive to a heat source or heat sink temperature variation. Therefore, stable temperatures operation temperatures are recommended. On the other hand, HFO$1336 \mathrm{mzz}(\mathrm{Z})$ would be the optimal refrigerant when there is a high heat source temperature. Moreover, it could provide different heat production temperatures with similar COP and VHC. Thus, it would be recommended for applications where a range of heat production temperature is necessary at constant heat source temperature. 

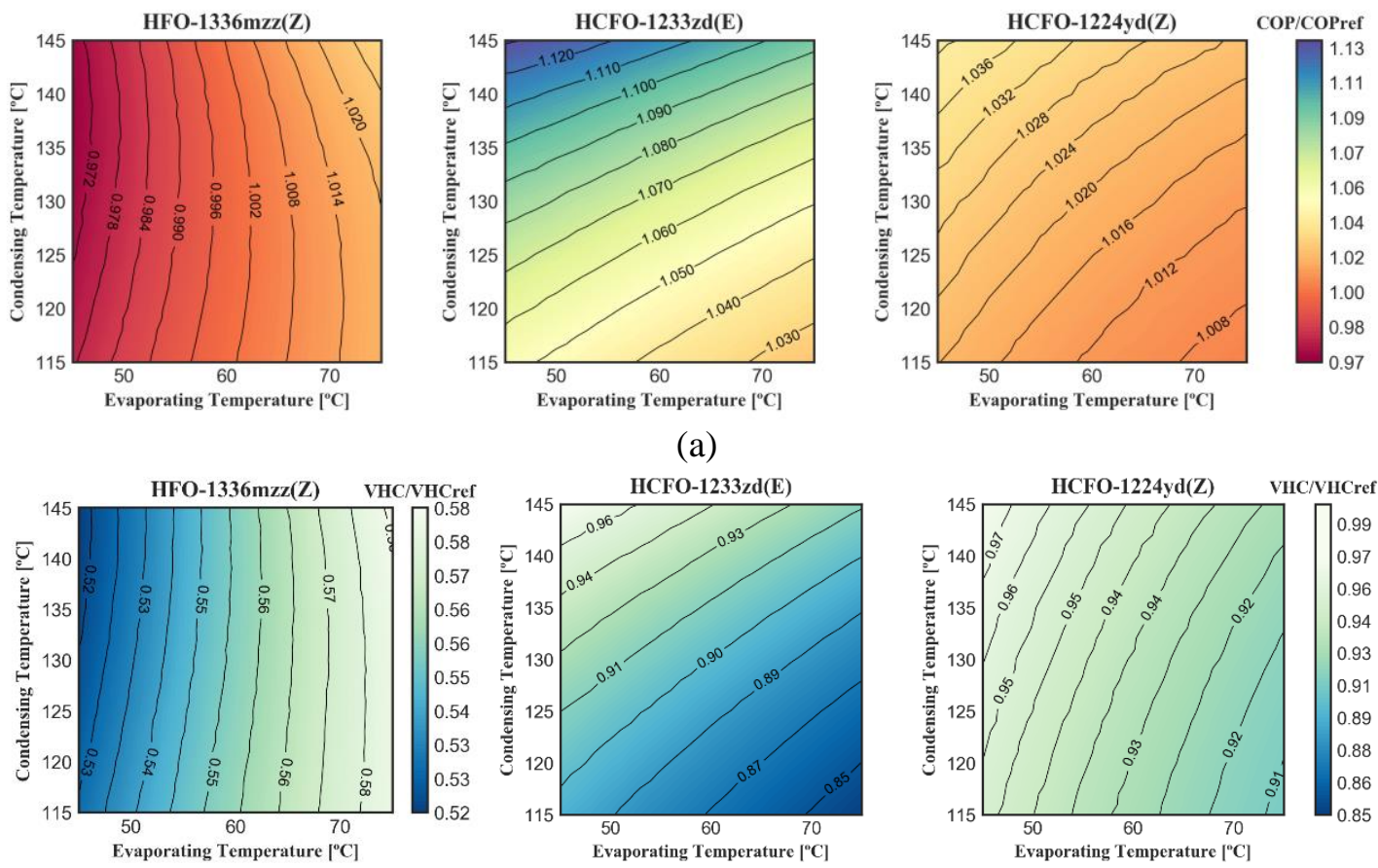

(a)
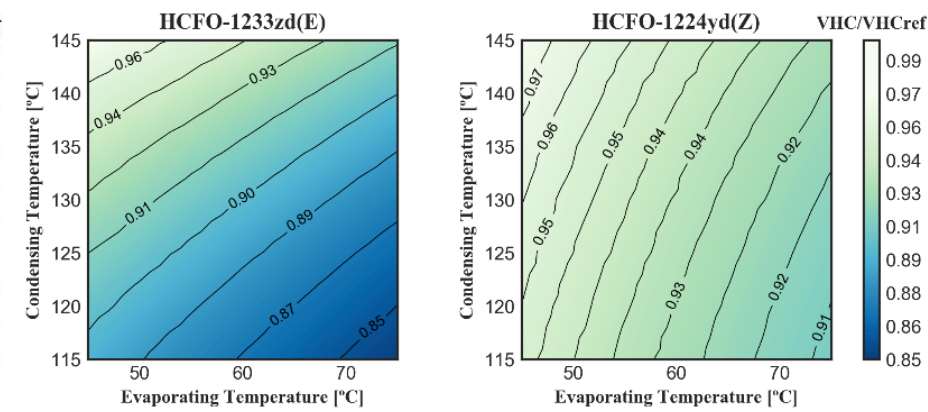

(b)

Fig. 12. Mapping of the guideline operating conditions of the alternative refrigerant: a)

$\mathrm{COP} / \mathrm{COP}_{\text {ref }}$ and b) $\mathrm{VHC} / \mathrm{VHC}_{\text {ref }}$

\section{Total Equivalent Warming Impact (TEWI) evaluation}

To analyse in deep the benefits of the proposed low GWP alternatives, an environmental impact evaluation that includes the effect of refrigerant leakage and energy consumption becomes necessary. Thus, the Total Equivalent Warming Impact (TEWI) of each refrigerant has been calculated to quantify the equivalent $\mathrm{CO}_{2}$ emission due to the accidental losses of refrigerant (direct emissions) and to the energy consumption of the HTHP system (indirect emissions). This method gives an appropriate approximation to the real environmental impact of vapour compression systems, and it is easy to apply. TEWI method is based on Eq. $(10)[33,38]$.

$$
T E W I=G W P \cdot L \cdot n+G W P \cdot m_{r} \cdot(1-\alpha)+n \cdot E_{a} \cdot \beta
$$

Previous research that includes TEWI analysis has been found in refrigeration and heat pump systems, but not in HTHPs. Therefore, this paper proposes some necessary assumptions that can be considered in this application. The constant condensing temperature of $145^{\circ} \mathrm{C}$ and three different evaporating temperatures, 45,60 and $75^{\circ} \mathrm{C}$, have been analysed. The HTHP evaporator exchanges $100 \mathrm{~kW}$ waste heat during 7884 hours per year ( $90 \%$ of the time). The lifespan of the system $(n)$ is considered 15 years.

The IPCC recommended annual leakage rate for indirect refrigeration systems contained in machinery rooms is 5\% of the total refrigerant charge [39], and due to its similarity, this value is also considered for HTHPs systems in this application. The recycling factor of the refrigerant $(\alpha)$ is omitted for this comparison. Finally, the indirect emission factor $(\beta)$ value is taken from the one proposed for the European Union by the European Environment Agency, $275.9 \mathrm{~g} \mathrm{CO}_{2} \mathrm{kWh}^{-}$ ${ }^{1}[40]$.

Fig. 13 shows the total equivalent $\mathrm{CO}_{2}$ emissions using each refrigerant for a constant condensing temperature, with and without IHX and for three different evaporating temperatures. Moreover, the resulting reduction in emissions using the alternatives compared to the reference fluid, HFC$245 \mathrm{fa}$, is presented in the figure. HFCO-1233zd(E) achieves the highest reduction, between 45 
and $61 \%$, followed by HFC-1224yd(Z). Although HCFO-1233zd(E) and HCFO-1224yd(Z) present similar suction volumetric flow rate to HFC-245fa, HFO-1336mzz(Z). The highest reductions are seen operating at high evaporation temperatures due to the higher improvement of COP. Moreover, the IHX addition is more significant at low evaporation temperatures, achieving emission reductions between 1 and 7\%, depending on the refrigerant.

Thus, the TEWI evaluation shows that HCFO-1224yd(Z), HCFO-1233zd(E) and HFO$1336 \mathrm{mzz}(\mathrm{Z})$ obtain a significant total equivalent $\mathrm{CO}_{2}$ emissions reduction compared to the reference fluid HFC-245fa because their direct emissions are negligible, and the indirect ones are mostly lower. Therefore, the utilisation of these low GWP alternatives can highly contribute to climate change mitigation.

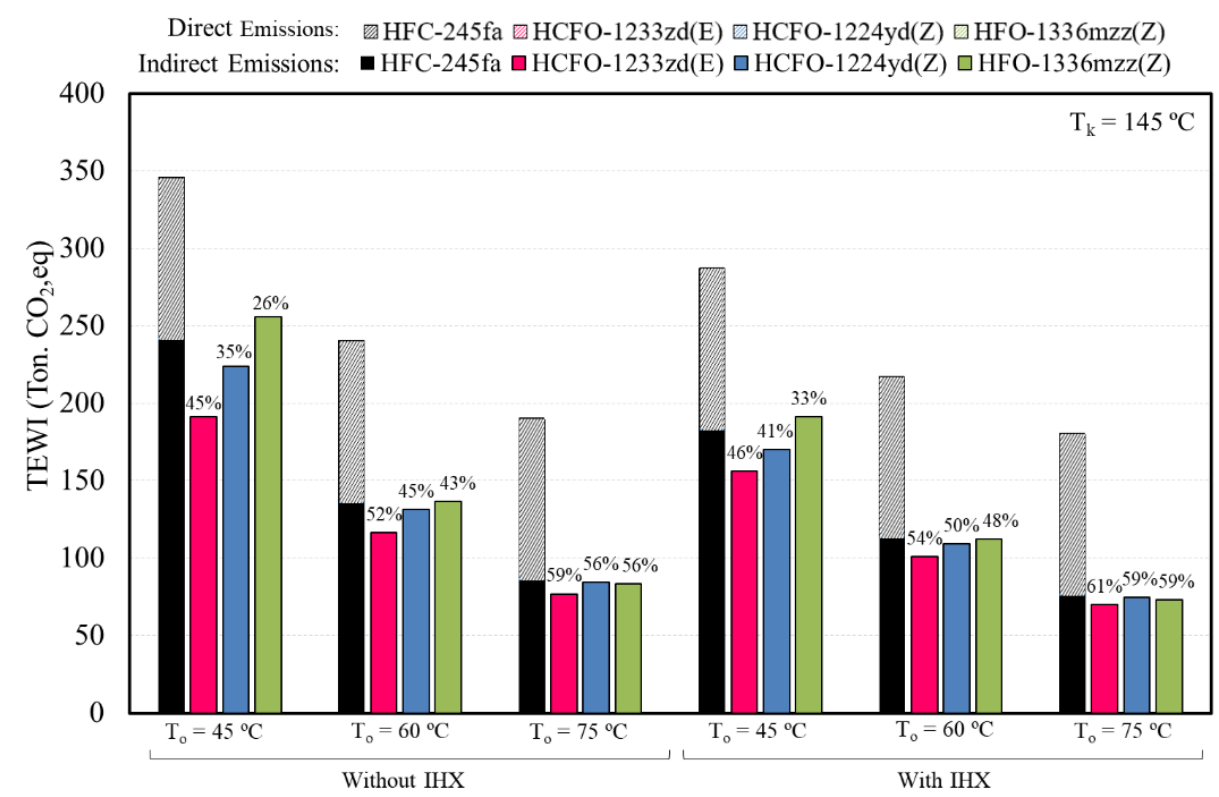

Fig. 13. TEWI at a constant condensing temperature of $145^{\circ} \mathrm{C}$ and percentage reduction of the total equivalent $\mathrm{CO}_{2}$ emissions for the low GWP alternatives compared to the reference fluid HFC-245fa.

\section{Conclusions}

This paper presented a preliminary thermodynamic study of the new low GWP alternatives HCFO-1233zd(E), HCFO-1224yd(Z) and HFO-1336mzz(Z) for the replacement of HFC-245fa in HTHPs for low-grade waste heat recovery. Considering the lack of research for these refrigerants in this application, this paper includes a study of the properties and a discussion of the theoretical results using a single-stage cycle and IHX configuration. Moreover, the minimum superheat required for each refrigerant and the IHX sensibility have been analysed, included then in a refrigerant guideline and the environmental impact analysis.

Alternative refrigerants present comparable thermodynamic and transport properties to HFC$245 \mathrm{fa}$. Their higher critical temperature allows the increase of the heating production temperature in possible future developments. The mapping of the minimum superheat requirement to ensure a dry compression show comparable values for HCFO-1233zd(E) and HCFO-1224yd(Z) with 7.1 and $4.4 \mathrm{~K}$, respectively. Nevertheless, $\mathrm{HFO}-1336 \mathrm{mzz}(\mathrm{Z})$ requires a minimum superheat of 19.2 K. The IHX presents comparable response for HFC-245fa, HCFO-1224yd(Z) and HFO$1336 \mathrm{mzz}(\mathrm{Z})$, whereas higher benefit in COP is observed for HCFO-1233zd(E).

The simulation analysis has been carried out using a single-stage cycle with and without IHX, varying the evaporating temperature from 45 to $75^{\circ} \mathrm{C}$ and the condensing temperature from 115 to $145{ }^{\circ} \mathrm{C}$. The conclusions reached from the simulation results favour the utilisation of 
refrigerants considered. HCFO-1233zd(E) improves the COP about 27\% whereas HFO$1336 \mathrm{mzz}(\mathrm{Z})$ and HCFO-1224yd(Z) show an improvement about 21 and 17\%, respectively. HFO$1336 \mathrm{mzz}(\mathrm{Z})$ shows a relative increment up to $80 \%$, and therefore, higher compressor and installation size are expected for this refrigerant than the reference fluid.

Finally, the optimal operation for HCFO-1233zd(E) and HCFO-1224yd(Z) would be located at constant heat source temperatures and higher heating production temperature. HFO-1336mzz(Z) could provide different heat production temperatures with similar COP. The TEWI analysis presents an approximate reduction of $60 \%$ of the equivalent $\mathrm{CO}_{2}$ emissions for the low GWP alternatives, being HCFO-1233zd(E) the refrigerant with highest reduction.

\section{Acknowledgements}

The authors acknowledge the Spanish Government for the financial support under projects ENE2015-70610-R, RTC-2017-6511-3 and grant FJCI-2016-28324. Furthermore, the authors acknowledge the Universitat Jaume I (Castellón de la Plana, Spain) for the financial support under the projects P1-1B2015-38 and, especially, UJI-B2018-24. Moreover, Carlos Mateu-Royo would like to acknowledge the funding received through the PhD grant PREDOC/2017/41. Finally, the authors want to acknowledge the Regional Government for the financial support under grant FEDEGENT/2018/002.

\section{References}

[1] United Nations, The Paris Agreement (English version), Available at: Http://Unfccc.Int/Files/Essential_background/Convention/Application/Pdf/English_paris _agreement. (2015).

[2] IPCC, Climate Change 2014: Synthesis Report. Contribution of Working Groups I, II and III to the Fifth Assessment Report of the Intergovernmental Panel on Climate Change [Core Writing Team, R.K. Pachauri and L.A. Meyer (eds.)]., Geneva, Switzerland,. (2014).

[3] C. Forman, I.K. Muritala, R. Pardemann, B. Meyer, Estimating the global waste heat potential, Renew. Sustain. Energy Rev. 57 (2016) 1568-1579. doi:10.1016/j.rser.2015.12.192.

[4] M.A.R. Eisa, R. Best, F.A. Holland, Working fluids for high temperature heat pumps, J. Heat Recover. Syst. 6 (1986) 305-311. doi:10.1016/0198-7593(86)90116-5.

[5] J.W. Linton, Description and Test Results of a High Temperature Heat Pump Test Facility, in: Heat Pumps, 1990: pp. 455-465. doi:10.1016/B978-0-08-040193-5.50055-9.

[6] J.W. Linton, W.K. Snelson, An Overview of Current High Temperature Heat Pump Technology, in: Heat Pumps Energy Effic. Environ. Prog., 1993: pp. 217-227. doi:10.1016/B978-0-444-81534-7.50031-0.

[7] United Nations, Montreal Protocol on Substances that Deplete the Ozone Layer, United Nations, New York, NY, USA. (1987).

[8] J. Brown, Potential R-114 replacement refrigerants, ASHRAE Trans. (2008).

[9] C. Arpagaus, F. Bless, M. Uhlmann, J. Schiffmann, S.S. Bertsch, High temperature heat pumps: Market overview, state of the art, research status, refrigerants, and application potentials, Energy. 152 (2018) 985-1010. doi:10.1016/J.ENERGY.2018.03.166.

[10] The European Parliament and the Council of the European, Union, Regulation (EU) No 517/2014 of the European Parliament and the Council of 16 April 2014 on fluorinated 
greenhouse gases and repealing Regulation (EC), No 842/2006. Off. J. Eur. Union 150, 195-230. (2014).

[11] J.M. Calm, The next generation of refrigerants - Historical review, considerations, and outlook, Int. J. Refrig. 31 (2008) 1123-1133. doi:10.1016/j.ijrefrig.2008.01.013.

[12] O. Bamigbetan, T.M. Eikevik, P. Nekså, M. Bantle, Review of vapour compression heat pumps for high temperature heating using natural working fluids, Int. J. Refrig. 80 (2017) 197-211. doi:10.1016/j.ijrefrig.2017.04.021.

[13] J.S. Brown, C. Zilio, A. Cavallini, The fluorinated olefin R-1234ze(Z) as a hightemperature heat pumping refrigerant, Int. J. Refrig. 32 (2009) 1412-1422. doi:10.1016/j.ijrefrig.2009.03.002.

[14] S. Fukuda, C. Kondou, N. Takata, S. Koyama, Low GWP refrigerants R1234ze(E) and R1234ze(Z) for high temperature heat pumps, Int. J. Refrig. 40 (2014) 161-173. doi:10.1016/j.ijrefrig.2013.10.014.

[15] C. Kondou, S. Koyama, Thermodynamic assessment of high-temperature heat pumps using low-GWP HFO refrigerants for heat recovery, Int. J. Refrig. 53 (2015) 126-141. doi:10.1016/j.ijrefrig.2014.09.018.

[16] A. Mota-babiloni, J. Navarro-esbrí, F. Molés, A. Barragán-Cervera, B. Peris, G. Verdú, A review of refrigerant R1234ze ( E ) recent investigations, Appl. Therm. Eng. 95 (2016) 211-222. doi:10.1016/j.applthermaleng.2015.09.055.

[17] K. Kontomaris, A zero-ODP, low GWP working fluid for high temperature heating and power generation from low temperature heat: DR-2, Proc. JRAIA Int. Symp. 2012. (2012) 212-216.

[18] K. Kontomaris, Zero-ODP, Low-GWP, Nonflammable Working Fluids for High Temperature Heat Pumps, ASHRAE Annu. Conf. Seattle, Washington, July 1, 2014. (2014) 1-40.

[19] K. Kontomaris, L.D. Simoni, M. Nilsson, T. Hamacher, H. Nes, Combined Heat and Power From Low Temperature Heat: HFO-1336mzz ( Z ) as a Working Fluid for Organic Rankine Cycles, Int. Compress. Eng. Refrig. Air Cond. High Perform. Build. Conf. (2016) 1-10.

[20] E. Gorgy, Nucleate boiling of low GWP refrigerants on highly enhanced tube surface, Int. J. Heat Mass Transf. 96 (2016) 660-666. doi:10.1016/j.jheatmasstransfer.2016.01.057.

[21] H.W. Byun, D.H. Kim, S.H. Yoon, C.H. Song, K.H. Lee, O.J. Kim, Pool boiling performance of enhanced tubes on low GWP refrigerants, Appl. Therm. Eng. 123 (2017) 791-798. doi:10.1016/j.applthermaleng.2017.05.009.

[22] F. Molés, J. Navarro-Esbrí, B. Peris, A. Mota-Babiloni, Experimental evaluation of HCFO-1233zd-E as HFC-245fa replacement in an Organic Rankine Cycle system for low temperature heat sources, Appl. Therm. Eng. 98 (2016). doi:10.1016/j.applthermaleng.2016.01.011.

[23] D. Lee, D. Kim, S. Park, J. Lim, Y. Kim, Evaporation heat transfer coefficient and pressure drop of R-1233zd(E) in a brazed plate heat exchanger, Appl. Therm. Eng. 130 (2018) 1147-1155. doi:10.1016/J.APPLTHERMALENG.2017.11.088.

[24] C. Mateu-Royo, J. Navarro-Esbrí, A. Mota-Babiloni, M. Amat-Albuixech, F. Molés, Theoretical evaluation of different high-temperature heat pump configurations for lowgrade waste heat recovery, Int. J. Refrig. (2018). doi:10.1016/j.ijrefrig.2018.04.017. 
[25] ANSI/ASHRAE, Designation and Safety Classification of Refrigerants, Stand. 34. (2016).

[26] AGC Chemicals, AMOLEA® 1224yd, Technical information, ASAHI Glas. Co. (2017) $1-18$.

[27] H. Fukushima, Masato Hayamizu, M. Hashimoto, Thermodynamic Properties of LowGWP Refrigerant for Centrifugal Chiller, Int. Refrig. Air Cond. Conf. (2016).

[28] E.W. Lemmon, M.L. Huber, M.O. McLinden, NIST Standard Reference Database 23: Reference Fluid Thermodynamic and Transport Properties-REFPROP, Version 9.1, Natl. Inst. Stand. Technol. Stand. Ref. Data Program, Gaithersburg, MD, USA. (2013).

[29] ASHRAE, ASHRAE Handbook Fundamentals, Am. Soc. Heating, Refrig. AirConditioning Eng. (2017).

[30] K. Kontomaris, Low-GWP, Nonflammable Working Fluids for High Temperature Heat Pumps, ASHRAE 2014 Annu. Conf. Seattle, Washington, USA (June 28- July 2). (2014).

[31] H. Moisi, R. Rieberer, Refrigerant Selection and Cycle Development for a High Temperature Vapor Compression Heat Pump, 12th IEA Heat Pump Conf. 2017, Rotterdam. (2017) 1-10.

[32] K.O. Patten, D.J. Wuebbles, Atmospheric lifetimes and Ozone Depletion Potentials of trans-1-chloro-3,3,3-trifluoropropylene and trans-1,2-dichloroethylene in a threedimensional model, Atmos. Chem. Phys. 10 (2010) 10867-10874. doi:10.5194/acp-10$10867-2010$.

[33] P. Makhnatch, R. Khodabandeh, The role of environmental metrics (GWP, TEWI, LCCP) in the selection of low GWP refrigerant, Energy Procedia. 61 (2014) 2460-2463. doi:10.1016/j.egypro.2014.12.023.

[34] J.R. Juhasz, L.D. Simoni, a Review of Potential Working Fluids for Low Temperature Organic Rankine Cycles in Waste Heat Recovery, 3rd Int. Semin. ORC Power Syst. (2015) 1-10.

[35] S. Klein, Engineering Equation Solver (EES) V10.2., Fchart Software, Madison, USA Www.Fchart.Com. (2006).

[36] E. Granryd, I. Ekroth, P. Lundqvist, A. Melinder, B. Palm, P. Rohlin, Refrigeration Engineering, K. Tek. Högskolan. (1999).

[37] B. Palm, Hydrocarbons as refrigerants in small heat pump and refrigeration systems - A review, Int. J. Refrig. 31 (2008) 552-563. doi:10.1016/j.ijrefrig.2007.11.016.

[38] AIRAH, Methods of calculating Total Equivalent Warming Impact (TEWI), Best Pract. Guidel. Aust. Inst. Refrig. Air Cond. Heat. (2012).

[39] IPCC, IPCC/TEAP special report on safeguarding the ozone layer and the global climate system: Issues related to hydrofluorocarbons and perfluorocarbons, Cambridge Publ. Intergov. Panel Clim. Chang. [by] Cambridge Univ. Press. (2005).

[40] EEA, Overview of electricity production and use in Europe, Eur. Enviroment Agency. (2016). 